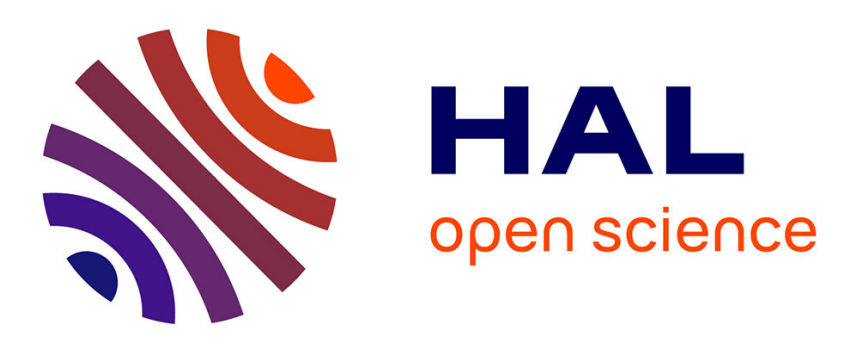

\title{
Development of a novel highly anti-proliferative family of gold complexes: $\mathrm{Au}(\mathrm{I})$-phosphoniumphosphines
}

Benjamin Rousselle, Florence Bouyer, Jérôme Bayardon, Myriam Laly, François Ghiringhelli, Yoann Rousselin, Ewen Bodio, Raluca Malacea-Kabbara

\section{- To cite this version:}

Benjamin Rousselle, Florence Bouyer, Jérôme Bayardon, Myriam Laly, François Ghiringhelli, et al.. Development of a novel highly anti-proliferative family of gold complexes: $\mathrm{Au}(\mathrm{I})$ phosphoniumphosphines. Dalton Transactions, 2021, 50, pp.4880-4889. 10.1039/D0DT03708G . hal03292599

\section{HAL Id: hal-03292599 \\ https://hal.science/hal-03292599}

Submitted on 20 Jul 2021

HAL is a multi-disciplinary open access archive for the deposit and dissemination of scientific research documents, whether they are published or not. The documents may come from teaching and research institutions in France or abroad, or from public or private research centers.
L'archive ouverte pluridisciplinaire HAL, est destinée au dépôt et à la diffusion de documents scientifiques de niveau recherche, publiés ou non, émanant des établissements d'enseignement et de recherche français ou étrangers, des laboratoires publics ou privés. 


\title{
Development of a novel highly anti-proliferative family of gold complexes: Au(I)-phosphonium- phosphines
}

\author{
Benjamin Rousselle, a Florence Bouyer,b Jérôme Bayardon, a Myriam Laly,a François Ghiringhelli,b \\ Yoann Rousselin, a Ewen Bodio, *a and Raluca Malacea-Kabbara*a
}

A family of gold(I)-phosphonium-phosphines complexes was synthesized thanks to an efficient 5-step strategy, which involve a phospha-Fries rearrangement. It enables the facile variation of the phosphonium moiety. All the complexes along with the synthetic intermediate was fully characterized (a crystal structure was obtained for two of them). The antiproliferative properties of the six novel complexes were evaluated on three human cancer cell lines (A549, MDA-MB-231, and SW480) and compared to three benchmark anticancer drugs used in clinics (oxaliplatin, 5fluorouracil, and paclitaxel) and to a phosphonium-free gold(I) complex [AuPPh3AuBr]. All the gold(I) complexes, containing a phosphonium, displayed strong anti-proliferative properties. They were more efficient than oxaliplatin and than 5-fluorouracil, and one of the complexes was even more efficient than paclitaxel.

\section{INTRODUCTION}

Phosphonium-phosphine is a class of compounds, which is not so common. They were mainly used as ligands - chiral or not - for catalysis or as Wittig intermediates. ${ }^{1-5}$ They were also used to give humidity-sensitive properties to polyelectrolytes copolymers. ${ }^{6}$ However, in the present study, we are interested in their biological applications. Phosphonium is known to be a good vector to target mitochondria, especially in cancer cells. ${ }^{7}$ Indeed, it was reported that phosphonium can accumulate ten times more in cancer cells than in healthy ones, because the negative potential of cancer cells mitochondria is higher than for healthy ones $(163 \mathrm{mV}$ vs 104$) .^{8}$ Moreover, the association of the water solubility brought by the positive charge and the lipophilicity due to its delocalization facilitate the crossing of cell membrane of phosphonium derivatives. ${ }^{7}$ These are some of the reasons why phosphoniums were used for vectorizing antioxidant, ${ }^{9}$ antibacterial, ${ }^{10}$ or anticancer ${ }^{11}$ agents. Concerning, phosphonium-phosphine, Nakagawa and coll. reported an elegant study, in which they developed an OFF/ON smart probe for detecting reactive oxygen species (ROS) in mitochondria. ${ }^{12}$ Bagherjeri and coll. chose to use the coordination properties of the phosphine to develop a zwitterionic $\mathrm{Hg}(\mathrm{II})$-based antibacterial complex, where they took advantage of the phosphonium to counterbalance the negative charge of the mercury complex. ${ }^{13}$

In the present study, we decided to combine the vectorization properties of the phosphonium to the ability of phosphine to coordinate gold(I) in order to develop novel anti-cancer agents. Among the metal-based complexes, Au(I)-phosphine complexes attract increasing interest since the repurposing of auranofin - an anti-rheumatoid drug - for anticancer applications. ${ }^{14}$ Gold(I) complexes were extensively studied by many researchers including our group. ${ }^{15-26}$ Contrary to platinum derivatives, the main hypothesis concerning the mechanism of action of gold(I)-based phosphine complexes is the inhibition of thio and/or seleno-cysteine enzymes, such as thioredoxine reductases (TrxRs), via the coordination of gold center to thiols or selenols. TrxRs are in charge of the regulation of oxidative stress and their inhibition leads to the increase of ROS and to apoptosis. ${ }^{27-29}$ Based on this observation, we wanted to take advantage of the phosphonium to vectorise the $\mathrm{Au}(\mathrm{I})$-phosphine complex to the mitochondria, where TrxR2 is located. Moreover, the presence of the phosphonium will improve the solubility of the gold complexes in biological media (Figure 1).

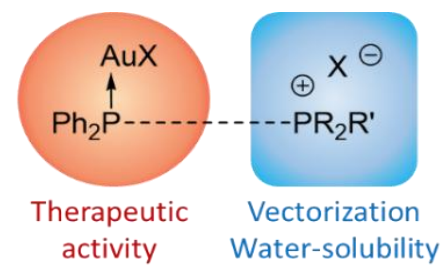

Figure 1: General structure of the targeted complexes

\section{RESULTS AND DISCUSSION}

Synthesis of gold-phosphonium-phosphine complexes la-f

The synthesis of the phosphonium-phosphine ligands is based on the quaternisation reaction of various phosphines with [(2-bromo methyl)phenyl]diphenylphosphine borane 4. This halogenated intermediate was prepared via a three-step synthetic route starting from the commercially available 2-bromobenzyl alcohol (1) (Scheme 1). In the first step, the 
reaction of 1 with chlorodiphenylphosphine in presence of ethyldiisopropylamine followed by $\mathrm{BH}_{3}$. DMS addition gave the 2bromobenzyl phosphinite borane derivative 2 in $83 \%$ yield. Its ${ }^{31} \mathrm{P}$ NMR spectrum presents a signal at $107.2 \mathrm{ppm}$ in $\mathrm{CD}_{2} \mathrm{Cl}_{2}$ the characteristic region for phosphinite borane derivatives. Metal-halogen exchange takes place when tBuLi is added to 2 to further give, by an elegant phospha-Fries rearrangement, the 2-hydroxymethylphosphine borane derivative $\mathbf{3}$ in $\mathbf{7 7 \%}$ yield. This rearrangement is based on the reaction described by Melvin ${ }^{30}$ in 1991 with aryl phosphates and further developed by Beak ${ }^{31}$ or Jugé ${ }^{32}$ with phosphinite borane derivatives. Significant change is observed on ${ }^{31} \mathrm{P}$ NMR spectrum with the appearance of a signal at $18.3 \mathrm{ppm}$. In the last step, the Appel reaction allowed to convert the alcohol $\mathbf{3}$ in the corresponding alkyl halide $\mathbf{4}$ in $83 \%$ yield using triphenylphosphine and tetrabromomethane at room temperature. Minor shift on the ${ }^{31} \mathrm{P}$ NMR spectrum was observed for this step $(4: \delta=19.9 \mathrm{ppm})$. On the ${ }^{1} \mathrm{H}$ NMR spectrum, the doublet corresponding to the methylene of compound $\mathbf{3}(\delta=4.54 \mathrm{ppm}, J=5.7 \mathrm{~Hz})$ is transformed into a singlet for compound 4 due to the loss of coupling with the hydroxyl proton.

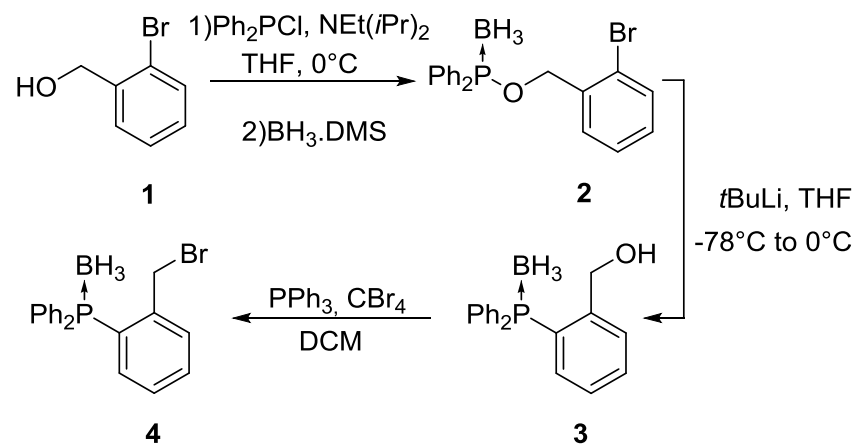

Scheme 1: Synthesis of (o-bromomethylphenyl) phosphine borane 4

The halogenated phosphine borane derivative $\mathbf{4}$ was further reacted with various phosphines to give the corresponding phosphonium-phosphine ligands 5 (Scheme 2). 2.5 equivalents of the phosphine $P R_{2} R^{\prime}$ were necessary to enable the nucleophilic substitution on the bromomethyl moiety and the decoordination of the borane group in one single step. This methodology avoids the homoleptic quaternisation of bromo derivative $\mathbf{4}$ and gives the desired phosphonium phosphine ligands $\mathbf{5}$ with yields up to $91 \%$. Six different phosphines wearing alkyl or aryl group with electron withdrawing or electron donating groups were used for this study. The ${ }^{31} \mathrm{P} N M R$ spectra of the ligands 5 presents a signal ranging from -14 to -17 ppm for the phosphine moiety and a second one ranging from 20 to $26 \mathrm{ppm}$ for the phosphonium group (Table 1) excepting ligand $\mathbf{5 d}$ which gives a signal at $+32.6 \mathrm{ppm}$ for the phosphonium group. This chemical shift is very similar to that described in the literature for methyltributylphosphonium tetrafluoroborate at $+32.8 \mathrm{ppm}^{33}$

Gold complexes la-f were readily synthesized by reacting the phosphonium-phosphines 5a-f with bromo(tetrahydrothiophene) gold(I) precursor in dichloromethane at room temperature (Scheme 2). The reaction was monitored by ${ }^{31} \mathrm{P}$ NMR and a significant shift for the phosphine moiety could be observed from -15 ppm to $24-28 \mathrm{ppm}$. After one hour at room temperature, the reaction is finished, and the corresponding gold complexes la-f were obtained with yields up to $94 \%$. It is worth noting that the use of $[\mathrm{Au}(\mathrm{tht}) \mathrm{Br}]$ instead of $[\mathrm{Au}(\mathrm{tht}) \mathrm{Cl}]$ prevents the formation of a mixture of complexes. Indeed, when using $[\mathrm{Au}(\mathrm{tht}) \mathrm{Cl})]$, the bromide counter anion of $\mathbf{5}$ can exchange with the chlorido ligand of the gold complex leading to the formation of "P-Au-Cl" and "P-Au-Br" complexes.

The stability of the complexes la-If was investigated thanks to NMR studies. They were stable at least $72 \mathrm{~h}$ in DMSO and in presence of water (see ESI for details).
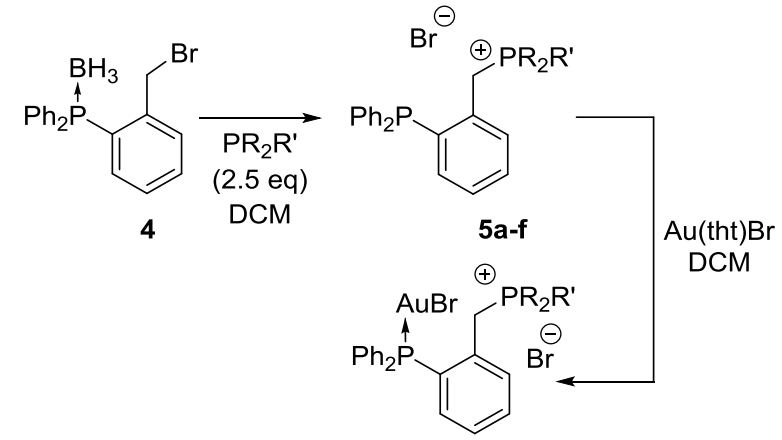

la-f

Scheme 2: Synthesis of ligand 5 by phosphine quaternization

Table 1: Structures, ${ }^{31} \mathrm{P}$ NMR data and yields for phosphonium-phosphines 5a-f 


\begin{tabular}{|c|c|c|c|c|}
\hline $\mathbf{N}^{\circ}$ & Structure & \multicolumn{2}{|c|}{${ }^{31}$ P NMR (ppm) } & Yield \\
\hline & & -15.12 & +22.97 & $87 \%$ \\
\hline $5 b$ & & -15.62 & +22.08 & $91 \%$ \\
\hline $5 c$ & & -17.24 & +20.72 & $82 \%$ \\
\hline $5 d$ & & -14.57 & +32.60 & $67 \%$ \\
\hline $5 e$ & $\mathrm{Br}^{\ominus}$ & -14.13 & +26.29 & $90 \%$ \\
\hline $5 f$ & & -15.53 & +21.75 & $80 \%$ \\
\hline
\end{tabular}

Table 2: Structures, ${ }^{31} \mathrm{P}$ NMR data and yields for gold(I) complexes la-f

\begin{tabular}{|c|c|c|c|c|}
\hline $\mathbf{N}^{\circ}$ & Structure & \multicolumn{2}{|c|}{${ }^{31}$ P NMR (ppm) } & yield \\
\hline la & & +22.66 & +25.98 & $80 \%$ \\
\hline Ib & & +21.76 & +26.07 & $94 \%$ \\
\hline Ic & & +21.71 & +26.03 & $64 \%$ \\
\hline Id & $\oplus$ & +26.91 & +33.43 & $80 \%$ \\
\hline le & $\|$ & +26.43 & +27.88 & $78 \%$ \\
\hline If & & +21.80 & +24.91 & $87 \%$ \\
\hline
\end{tabular}




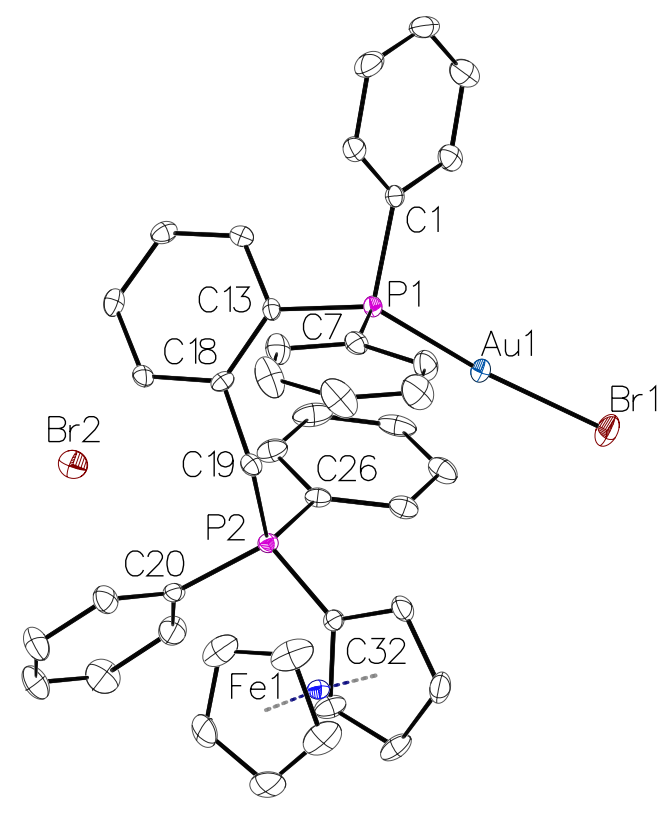

Figure 2: ORTEP view of complex le Au1-Br1: 2.4026(4); Au1-P1: 2.2373(9); P1-Au1-Br1: 172.73(2). Thermal ellipsoids are drawn at 50\%

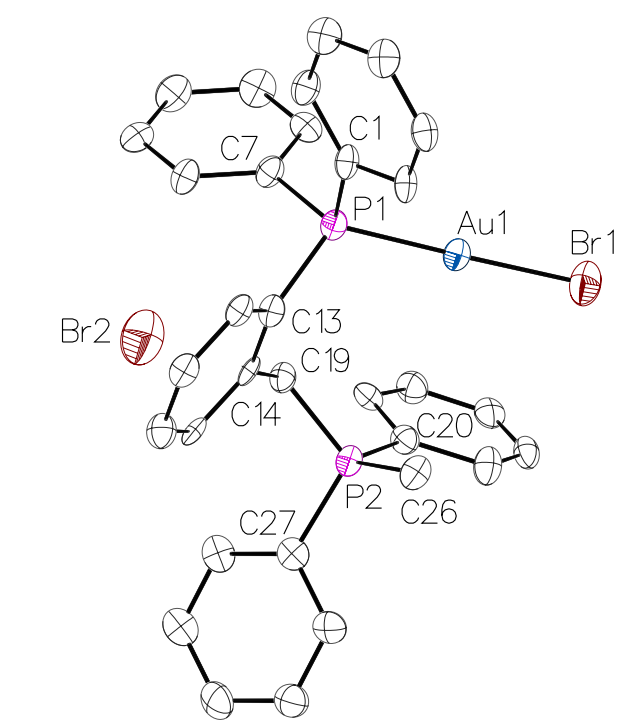

probability plot. Hydrogen atoms and DCM solvent are omitted for clarity.

Figure 3: ORTEP view of complex If Au1-Br1: 2.364(3); Au1-P1: 2.257(6); P1-Au1-Br1: 178.7(4). Thermal ellipsoids are drawn at 30\% probability plot. Hydrogen atoms and DCM solvent are omitted for clarity.

Their anti-proliferative properties were always better onto A549 than onto the other cell lines and most of the time lower onto SW480, except for complex Ib, which displays submicromolar $\mathrm{IC}_{50}$ for all the tested cancer cell lines. The results highlight a significant impact of the substituents of the phosphonium on anti-proliferative properties of the compounds. They can be qualitatively ranked as follow: $-\mathrm{P}^{+}(p-\mathrm{Tol})_{3}>--\mathrm{P}^{+}(\mathrm{Ph})_{2} \mathrm{Fc} \approx-\mathrm{P}^{+}(\mathrm{Ph})_{3}>-\mathrm{P}^{+}(\mathrm{Bu})_{3}>-\mathrm{P}^{+}(\mathrm{Ph})_{2} \mathrm{Me}>-\mathrm{P}^{+}(p-f l u o r o p h e n y l)_{3}$. Thus, there is no obvious correlation between anti-proliferative properties of the complexes and either the electron donating character of the substituents or their steric hindrance. It seems that the best results were obtained, when the positive charge of phosphonium can be delocalized on several aromatic substituents and when these aromatic rings are substituted with electron donating groups. The negative impact of $p$-fluorophenyle groups with respect to phenyl substituents on anti-proliferative properties was also observed by Bricklebank and coll.. ${ }^{35}$ 
Table 3: Antiproliferative activity of our complexes la-g, oxaliplatin, 5-FU, and paclitaxel on three cancer cell lines (A549, MDA-MB-231, and SW480)

\begin{tabular}{|c|c|c|c|}
\hline \multirow[b]{2}{*}{ Compound } & \multicolumn{3}{|c|}{$I C_{50}(\mu \mathrm{M})$} \\
\hline & A549 & MDA-MB-231 & SW480 \\
\hline la & $0.89 \pm 0.03$ & $1.81 \pm 1.20$ & $4.1 \pm 1.30$ \\
\hline lb & $0.34 \pm 0.02$ & $0.47 \pm 0.02$ & $0.44 \pm 0.04$ \\
\hline Ic & $3.17 \pm 0.50$ & $4.04 \pm 0.55$ & $9.36 \pm 1.75$ \\
\hline Id & $0.86 \pm 0.13$ & $3.18 \pm 1.07$ & $4.2 \pm 0.30$ \\
\hline le & $0.68 \pm 0.20$ & $1.72 \pm 0.20$ & $5.08 \pm 0.90$ \\
\hline If & $2.44 \pm 0.73$ & $4.28 \pm 0.34$ & $4.46 \pm 0.20$ \\
\hline $\lg$ & $38.1 \pm 7.79$ & $3.5 \pm 1.26$ & $14.2 \pm 2.20$ \\
\hline Oxaliplatin & $7.5 \pm 0.40$ & $14.4 \pm 1.90$ & $9.2 \pm 1.40$ \\
\hline 5-FU & $9.1 \pm 0.90$ & $22.3 \pm 0.60$ & $52.5 \pm 8.40$ \\
\hline Paclitaxel & $0.33 \pm 0.04$ & $0.39 \pm 0.02$ & $2.0 \pm 0.74$ \\
\hline
\end{tabular}

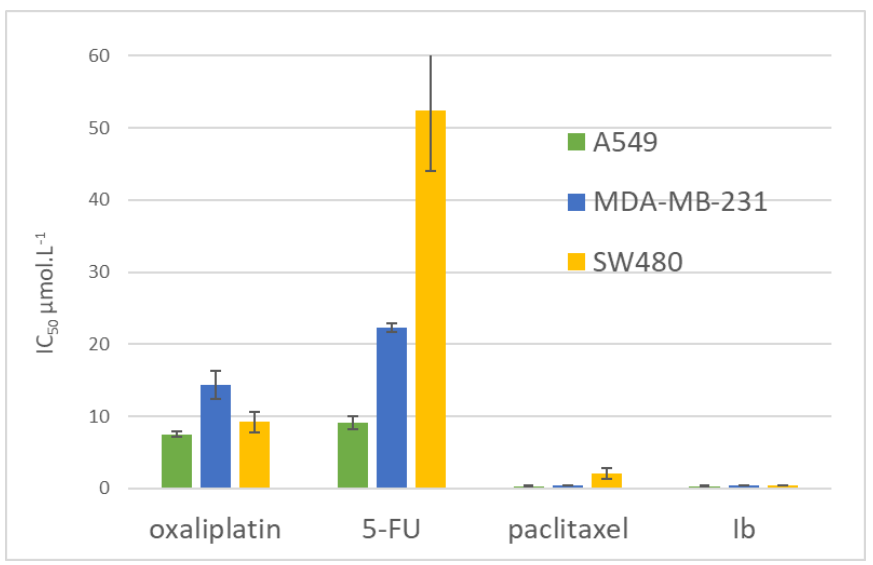

Figure 4: Comparison of the antiproliferative activity of our most active complex Ib on three cancer cell lines with clinically used anticancer agents

\section{Conclusions}

We reported an efficient strategy to synthesize phoSphonium-phosphine ligands and their corresponding gold(I) complexes. This strategy enables the facile introduction of different types of phosphoniums. The gold(I) complexes displayed IC $C_{50}$ in the low micromolar to the submicromolar range, which is better than 5-FU and oxaliplatin, and in the range of paclitaxel. These results are promising for future in vivo applications; even it would be interesting to synthesize analogues with phosphonium bearing other electron donating substituted aromatic rings to improve again their anti-proliferative properties. Moreover, it will be interesting to evaluate the impact of tethering a vector on biological properties in order to obtain selective therapeutic agents (i.e. it could be introduced via substitution of gold bromido ligand ${ }^{36}$ ).

\section{EXPERIMENTAL}

\section{Material and methods}

All synthetic manipulations were carried out using standard Schlenk techniques. All reagents were purchased either from Acros Organics, Sigma-Aldrich, Fischer Scientific, Alfa Aesar, TCl or ABCR and used without further purification. THF and dichloromethane were dried over alumina cartridges using a solvent purification system MB-SPS-800 model from $\mathrm{M}$. BRAUN. Column chromatography were conducted on silica gel 60-200 $\mu \mathrm{m}$ or 40-63 $\mu \mathrm{m}$ purchased from Sigma-Aldrich. NMR spectra $\left({ }^{1} \mathrm{H},{ }^{13} \mathrm{C},{ }^{13} \mathrm{C}-\mathrm{J}_{\text {mod }},{ }^{19} \mathrm{~F},{ }^{31} \mathrm{P}\right)$ were recorded with Brucker $300 \mathrm{MHz}, 500 \mathrm{MHz}$ or $600 \mathrm{MHz}$ apparatus, using tetramethylsilane as internal reference for ${ }^{1} \mathrm{H},{ }^{13} \mathrm{C} N M R$, phosphoric acid $(85 \%)$ as external reference for ${ }^{31} \mathrm{P}$ NMR. 
Abbreviations used to describe the multiplicity of the signal are: s (singlet), $d$ (doublet), $t$ (triplet), q (quartet), bs (broad signal), $m$ (multiplet). Mass spectra were performed under electrospray ionization conditions (ESI) with a Thermo LTQ Orbitrap XP.

\section{Single Crystal X-ray Diffraction}

All experimental data procedure and refinement are detailed in Supplementary Information. Data CCDC-2036897 and 2036898 for compound le and If contain the supplementary crystallographic data for this paper. These data can be obtained free of charge from The Cambridge Crystallographic Data Centre via www.ccdc.cam.ac.uk/data_request/cif

\section{Synthesis of the ligand precursor 4}

(2-Bromobenzyl)diphenylphosphinite borane (2)

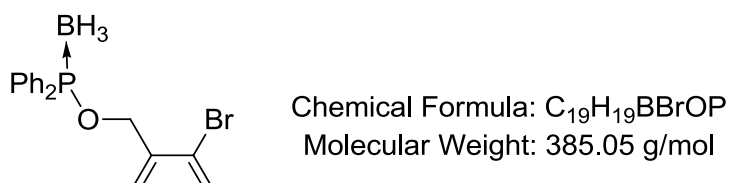

To a solution of 2-bromobenzyl alcohol (1.6 g, $8.5 \mathrm{mmol})$ in anhydrous THF (50 $\mathrm{mL})$ was added ethyldiisopropylamine $(5.0$ $\mathrm{mL}, 28.7 \mathrm{mmol})$. The mixture was cooled at $0^{\circ} \mathrm{C}$, then chlorodiphenylphosphine $(1.8 \mathrm{~mL}, 10.0 \mathrm{mmol})$ was added. After 30 min of stirring at $0^{\circ} \mathrm{C}$, the precipitated was removed by filtration using millipore and the solvent was evaporated. The resulting white solid was dissolved in anhydrous THF $(50 \mathrm{~mL})$, then $\mathrm{BH}_{3}$.DMS $(2 \mathrm{~mL}, 21.0 \mathrm{mmol})$ was added at RT. After $2 \mathrm{~h}$ of stirring, the resulting mixture was hydrolyzed by adding distilled water $(50 \mathrm{~mL})$. The aqueous phase was extracted with ethyl acetate $(3 \times 50 \mathrm{~mL})$. The organic phase was dried over $\mathrm{MgSO}_{4}$. After removal of the solvent, the residue was purified by recrystallization in methanol.

Yield $=83 \%, \mathrm{~m}=2.72 \mathrm{~g}, \mathrm{n}=7.1 \mathrm{mmol}$; white crystals. ${ }^{1} \mathrm{H}$ NMR $(300 \mathrm{MHz}$, Chloroform- $d) \delta 7.81-7.72\left(\mathrm{~m}, 4 \mathrm{H}, \mathrm{H}_{\text {aro }}\right), 7.58-7.41$ $\left(\mathrm{m}, 8 \mathrm{H}, \mathrm{H}_{\text {aro }}\right), 7.30\left(\mathrm{td}, J=7.5,1.3 \mathrm{~Hz}, 1 \mathrm{H}, \mathrm{H}_{\text {aro }}\right), 7.17\left(\mathrm{td}, J=7.7,1.8 \mathrm{~Hz}, 1 \mathrm{H}, \mathrm{H}_{\text {aro }}\right), 5.09\left(\mathrm{~d}, J=6.7 \mathrm{~Hz}, 2 \mathrm{H}, \mathrm{CH}_{2}\right), 1.50-0.15(\mathrm{~m}$, $\left.3 \mathrm{H}, \mathrm{BH}_{3}\right) ;{ }^{13} \mathrm{C}\left\{{ }^{1} \mathrm{H}\right\}$ NMR $\left(75 \mathrm{MHz}\right.$, Chloroform-d) $\delta 136.22\left(\mathrm{~d}, J=8.3 \mathrm{~Hz}, \mathrm{C}_{\text {aro }}\right), 132.50\left(\mathrm{~d}, J=53.5 \mathrm{~Hz}, \mathrm{C}_{\text {aro }}\right), 132.26\left(\mathrm{C}_{\text {aro }}\right), 132.11$ $\left(C_{\text {aro }}\right), 131.49$ (d, J = 11.4 Hz, $\left.C_{\text {aro }}\right), 129.84\left(\mathrm{~d}, J=1.5 \mathrm{~Hz}, \mathrm{C}_{\text {aro }}\right), 128.81\left(\mathrm{~d}, J=10.6 \mathrm{~Hz}, \mathrm{C}_{\text {aro }}\right), 127.65\left(\mathrm{C}_{\text {aro }}\right), 123.06\left(\mathrm{C}_{\text {aro }}\right), 68.43$ $\left(\mathrm{CH}_{2}\right)$; one carbon signal is not seen. ${ }^{31} \mathrm{P}\left\{{ }^{1} \mathrm{H}\right\}$ NMR $\left(202 \mathrm{MHz}\right.$, Methylene Chloride- $\left.d_{2}\right) \delta 107.20$ (br.s).

\section{[(2-hydroxymethyl)phenyl]diphenylphosphine borane (3)}

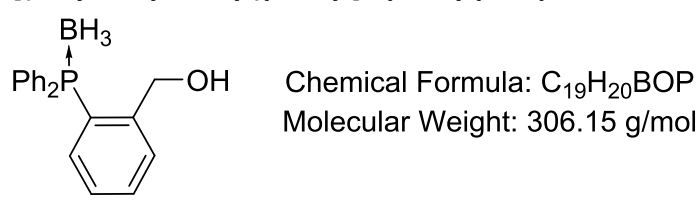

To a solution of phosphinite $2(2.37 \mathrm{~g}, 6.2 \mathrm{mmol})$ in THF $(10 \mathrm{~mL})$ was added dropwise $t$-BuLi $(9.1 \mathrm{~mL}, 15.4 \mathrm{mmol}, 1.7 \mathrm{M})$ at $78{ }^{\circ} \mathrm{C}$ under argon. After $2 \mathrm{~h} 30$ of stirring, the temperature was allowed to reach $0{ }^{\circ} \mathrm{C}$, the resulting mixture was hydrolyzed by adding distilled water $(5 \mathrm{~mL})$. The aqueous phase was extracted with DCM $(3 \times 10 \mathrm{~mL})$, then the organic phase dried over $\mathrm{MgSO}_{4}$. After removal of the solvent, the residue was purified over silica gel using EA/PE 1: 1 as eluent.

Yield $=77 \%, \mathrm{~m}=1.46 \mathrm{~g}, \mathrm{n}=4.8 \mathrm{mmol}$; white solid. ${ }^{1} \mathrm{H}$ NMR $\left(500 \mathrm{MHz}\right.$, Methylene Chloride- $\left.d_{2}\right) \delta 7.64$ (ddd, $J=7.7,4.2,1.4$ $\left.\mathrm{Hz}, 1 \mathrm{H}, \mathrm{H}_{\text {aro }}\right), 7.59-7.53\left(\mathrm{~m}, 7 \mathrm{H}, \mathrm{H}_{\text {aro }}\right), 7.50-7.44\left(\mathrm{~m}, 4 \mathrm{H}, \mathrm{H}_{\text {aro }}\right), 7.28-7.23\left(\mathrm{~m}, 1 \mathrm{H}, \mathrm{H}_{\text {aro }}\right), 6.96(\mathrm{ddd}, J=11.7,7.8,1.3 \mathrm{~Hz}, 1 \mathrm{H}$, $\left.\mathrm{H}_{\text {aro }}\right), 4.54\left(\mathrm{~d}, J=5.7 \mathrm{~Hz}, 2 \mathrm{H}, \mathrm{CH}_{2}\right), 2.32-2.24(\mathrm{~m}, 1 \mathrm{H}, \mathrm{OH}), 1.71-0.98\left(\mathrm{~m}, 3 \mathrm{H}, \mathrm{BH}_{3}\right) ;{ }^{13} \mathrm{C}\left\{{ }^{1} \mathrm{H}\right\} \mathrm{NMR}(75 \mathrm{MHz}$, Chloroform-d) $\delta$ $145.38\left(\mathrm{~d}, J=11.5 \mathrm{~Hz}, \mathrm{C}_{\mathrm{aro}}\right), 134.22\left(\mathrm{~d}, J=6.2 \mathrm{~Hz}, \mathrm{C}_{\mathrm{aro}}\right), 133.33\left(\mathrm{~d}, J=9.0 \mathrm{~Hz}, \mathrm{C}_{\mathrm{aro}}\right), 132.11\left(\mathrm{~d}, J=2.4 \mathrm{~Hz}, \mathrm{C}_{\mathrm{aro}}\right), 131.66(\mathrm{~d}, J=$ $\left.2.4 \mathrm{~Hz}, \mathrm{C}_{\text {aro }}\right), 131.22$ (d, J=8.8 Hz, $\left.\mathrm{C}_{\text {aro }}\right), 129.14$ (d, J=10.3 Hz, C aro), 129.08 (d, J=58.5 Hz, Caro), 127.89 (d, $\left.J=8.8 \mathrm{~Hz}, \mathrm{C}_{\text {aro }}\right)$, $127.33\left(\mathrm{~d}, J=53.9 \mathrm{~Hz}, \mathrm{C}_{\text {aro }}\right), 63.29\left(\mathrm{~d}, J=6.1 \mathrm{~Hz}, \mathrm{CH}_{2}\right) ;{ }^{31} \mathrm{P}\left\{{ }^{1} \mathrm{H}\right\} \mathrm{NMR}\left(202 \mathrm{MHz}\right.$, Methylene Chloride- $\left.d_{2}\right) \delta 18.30$ (br.s).

[(2-bromomethyl)phenyl]diphenylphosphine borane (4)<smiles>BrCc1ccccc1P[Pb]</smiles>

Chemical Formula: $\mathrm{C}_{19} \mathrm{H}_{19} \mathrm{BBrP}$ Molecular Weight: $369.05 \mathrm{~g} / \mathrm{mol}$

To a solution of [(2-hydroxymethyl)phenyl]diphenylphosphine borane 3 (1.44 g, $4.7 \mathrm{mmol})$ in DCM (5 mL), $\mathrm{CBr}_{4}$ (2.85 g, 8.6 $\mathrm{mmol})$ and $\mathrm{PPh}_{3}(2.47 \mathrm{~g}, 9.4 \mathrm{mmol})$ were successively added under argon. After two hours of stirring at RT, the solvent was removed and the residue was purified on silica gel using DCM/PE 1: 1 as eluent.

Yield $=83 \%, \mathrm{~m}=1.44 \mathrm{~g}, \mathrm{n}=3.9 \mathrm{mmol}$; white solid. ${ }^{1} \mathrm{H}$ NMR $\left(500 \mathrm{MHz}\right.$, Methylene Chloride- $\left.d_{2}\right) \delta 7.67$ (ddd, $J=7.8,4.2,1.2$ $\left.\mathrm{Hz}, 1 \mathrm{H}, \mathrm{H}_{\text {aro }}\right), 7.63-7.44\left(\mathrm{~m}, 11 \mathrm{H}, \mathrm{H}_{\text {aro }}\right), 7.28-7.22\left(\mathrm{~m}, 1 \mathrm{H}, \mathrm{H}_{\text {aro }}\right), 7.00$ (ddd, J = 11.6, 7.9, 1.3 Hz, $\left.1 \mathrm{H}, \mathrm{H}_{\text {aro }}\right), 4.63\left(\mathrm{~s}, 2 \mathrm{H}, \mathrm{H}_{\text {aro }}\right)$, 
$1.78-0.85\left(\mathrm{~m}, 3 \mathrm{H}, \mathrm{BH}_{3}\right) ;{ }^{13} \mathrm{C}\left\{{ }^{1} \mathrm{H}\right\}$ NMR (75 MHz, Chloroform-d) $\delta 138.71\left(\mathrm{~d}, J=10.4 \mathrm{~Hz}, \mathrm{C}_{\text {aro }}\right), 133.45\left(\mathrm{~d}, J=10.6 \mathrm{~Hz}, \mathrm{C}_{\text {aro }}\right)$, 133.28 (d, $\left.J=9.7 \mathrm{~Hz}, \mathrm{C}_{\text {aro }}\right), 133.19$ (d, $\left.J=8.9 \mathrm{~Hz}, \mathrm{C}_{\text {aro }}\right), 132.13$ (d, $\left.J=2.5 \mathrm{~Hz}, \mathrm{C}_{\text {aro }}\right), 131.54$ (d, $\left.J=2.5 \mathrm{~Hz}, \mathrm{C}_{\text {aro }}\right), 130.26$ (d, $J=$ $\left.57.0 \mathrm{~Hz}, \mathrm{C}_{\text {aro }}\right), 129.38$ (d, J = $\left.10.2 \mathrm{~Hz}, \mathrm{C}_{\text {aro }}\right), 128.98$ (d, $\left.J=10.3 \mathrm{~Hz}, \mathrm{C}_{\text {aro }}\right), 128.84$ (d, J = 58.0 Hz, $\left.\mathrm{C}_{\text {aro }}\right), 32.58\left(\mathrm{CH}_{2}\right) ;{ }^{31} \mathrm{P}\left\{{ }^{1} \mathrm{H}\right\} \mathrm{NMR}$ (202 MHz, Methylene Chloride- $d_{2}$ ) $\delta 19.90$ (br.s); IR ( $\left.\mathrm{cm}^{-1}\right)$ : 3059, 2389, 2354, 1478, 1434, 1214, 1102, 1058, 1027, 998, 761, $751,691,622,604,562,511,493,483,457,427$; HR-MS (ESI): $\mathrm{m} / \mathrm{z}$ calcd for $\mathrm{C}_{19} \mathrm{H}_{19} \mathrm{BBrPNa}[\mathrm{M}+\mathrm{Na}]^{+}: 391.03930$ Da; Found : 391.04037 Da.

\section{General synthesis of the phosphonium-phosphine ligands 5a-f}

All the phosphonium phosphines are prepared using the following procedure: To a solution of [(2bromomethyl)phenyl]diphenyl phosphine borane $4(0.5 \mathrm{mmol})$ in DCM $(2 \mathrm{~mL})$ was added the tertiary phosphine $(1.25$ $\mathrm{mmol}, 2.5$ equivalents). The reaction was stirred until completion ( $24-48 \mathrm{~h})$. After removing most of the solvent, $\mathrm{Et}_{2} \mathrm{O}(5$ $\mathrm{mL}$ ) was added and a precipitate appeared which was filtered and purified on silica gel using MeOH/DCM 1: 10 as eluent.

[(2-diphenylphosphanyl)phenyl]methyl-triphenylphosphonium bromide (5a)

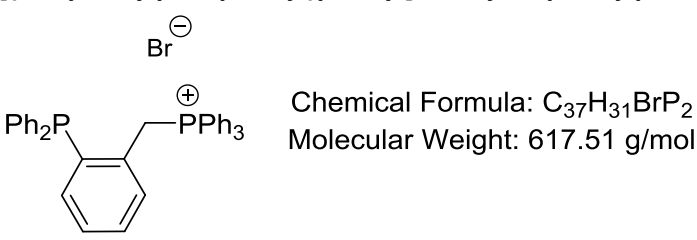

Stopped after 36 hours of reaction.

Yield $=87 \%, \mathrm{~m}=0.27 \mathrm{~g}, \mathrm{n}=0.44 \mathrm{mmol}$; white solid, $\mathrm{Mp}>250{ }^{\circ} \mathrm{C} .{ }^{1} \mathrm{H}$ NMR $\left(500 \mathrm{MHz}\right.$, Methylene Chloride- $\left.d_{2}\right) \delta 7.91-7.83$ $\left(\mathrm{m}, 3 \mathrm{H}, \mathrm{H}_{\text {aro }}\right), 7.71-7.62\left(\mathrm{~m}, 6 \mathrm{H}, \mathrm{H}_{\text {aro }}\right), 7.59-7.50\left(\mathrm{~m}, 6 \mathrm{H}, \mathrm{H}_{\text {aro }}\right), 7.39-7.34\left(\mathrm{~m}, 2 \mathrm{H}, \mathrm{H}_{\text {aro }}\right), 7.34-7.28\left(\mathrm{~m}, 6 \mathrm{H}, \mathrm{H}_{\text {aro }}\right), 7.29-7.21$ $\left(\mathrm{m}, 1 \mathrm{H}, \mathrm{H}_{\text {aro }}\right), 6.94-6.88\left(\mathrm{~m}, 4 \mathrm{H}, \mathrm{H}_{\text {aro }}\right), 6.87-6.81\left(\mathrm{~m}, 1 \mathrm{H}, \mathrm{H}_{\text {aro }}\right), 5.09\left(\mathrm{~d}, J=13.9 \mathrm{~Hz}, 2 \mathrm{H}, \mathrm{CH}_{2}\right) ;{ }^{13} \mathrm{C}\left\{{ }^{1} \mathrm{H}\right\} \mathrm{NMR}(75 \mathrm{MHz}$, Methylene chloride- $\left.d_{2}\right) \delta 138.6\left(\mathrm{dd}, J=6.4,12.8 \mathrm{~Hz}, \mathrm{C}_{\text {aro }}\right), 135.4\left(\mathrm{~d}, J=3.1 \mathrm{~Hz}, \mathrm{C}_{\text {aro }}\right), 134.8\left(\mathrm{~d}, J=3.1 \mathrm{~Hz}, \mathrm{C}_{\text {aro }}\right), 134.5$ (d, $J=9.7$ $\mathrm{Hz}, \mathrm{C}_{\text {aro }}$ ), 134.1 (d, J = 8.1 Hz, Caro), 133.7 (d, J = $19.3 \mathrm{~Hz}, \mathrm{C}_{\text {aro }}$ ), 132.0 (dd, J = 8.4, $25.2 \mathrm{~Hz}, \mathrm{C}_{\text {aro }}$ ), 131.1 (d, J = 4.6 Hz, Caro), $130.3\left(\mathrm{~d}, J=13.0 \mathrm{~Hz}, \mathrm{C}_{\text {aro }}\right), 130.0$ (d, J = 3.1 Hz, Caro), 129.5 (d, J = 3.8 Hz, C aro), 129.4 (Caro), 128.8 (d, J = 6.9 Hz, Caro), 117.4 (d, $\left.J=92.2 \mathrm{~Hz}, \mathrm{C}_{\text {aro }}\right), 29.9\left(\mathrm{dd}, J=24.0,48.0 \mathrm{~Hz}, \mathrm{CH}_{2}\right) ;{ }^{31} \mathrm{P}\left\{{ }^{1} \mathrm{H}\right\} \mathrm{NMR}\left(202 \mathrm{MHz}\right.$, Methylene Chloride- $\left.d_{2}\right) \delta 22.97(\mathrm{~s}),-15.12(\mathrm{~s}) ; \mathrm{IR}$ $\left(\mathrm{cm}^{-1}\right)$ : 3052, 3006, 2818, 2758, 1476, 1433, 1343, 1184, 1107, 1027, 994, 823, 787, 748, 722, 690; HR-MS (ESI): m/z calcd for $\mathrm{C}_{37} \mathrm{H}_{31} \mathrm{P}_{2}[\mathrm{M}-\mathrm{Br}]^{+}: 537.1896 \mathrm{Da}$; Found: 537.1904 Da.

[(2-diphenylphosphanyl)phenyl]methyl-tri(p-tolyl)phosphonium bromide (5b)

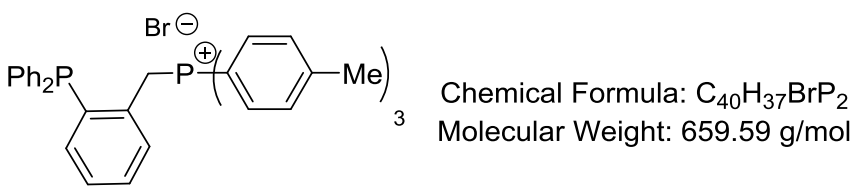

Stopped after 24 hours of reaction.

Yield $=91 \%, m=0.30 \mathrm{~g}, \mathrm{n}=0.45 \mathrm{mmol}$; white solid. ${ }^{1} \mathrm{H}$ NMR $\left(500 \mathrm{MHz}\right.$, Methylene Chloride- $\left.d_{2}\right) \delta 7.47-7.41\left(\mathrm{~m}, 6 \mathrm{H}, \mathrm{H}_{\mathrm{aro}}\right)$, 7.38 - $7.19\left(\mathrm{~m}, 14 \mathrm{H}, \mathrm{H}_{\text {aro }}\right), 7.20-7.15\left(\mathrm{~m}, 1 \mathrm{H}, \mathrm{H}_{\text {aro }}\right), 6.92-6.85\left(\mathrm{~m}, 5 \mathrm{H}, \mathrm{H}_{\text {aro }}\right), 4.88\left(\mathrm{dd}, J=13.8,1.0 \mathrm{~Hz}, 2 \mathrm{H}, \mathrm{CH}_{2}\right), 2.52(\mathrm{~s}, 9 \mathrm{H}$, $\left.\mathrm{CH}_{3}\right) ;{ }^{13} \mathrm{C}\left\{{ }^{1} \mathrm{H}\right\}$ NMR $\left(75 \mathrm{MHz}\right.$, Methylene chloride- $\left.d_{2}\right) \delta 147.30\left(\mathrm{~d}, J=3.2 \mathrm{~Hz}, \mathrm{C}_{\text {aro }}\right), 139.03-138.65\left(\mathrm{~m}, \mathrm{C}_{\text {aro }}\right), 135.19(\mathrm{~d}, J=3.1$ $\left.\mathrm{Hz}, \mathrm{C}_{\text {aro }}\right), 134.73\left(\mathrm{C}_{\text {aro }}\right), 134.63\left(\mathrm{~d}, J=10.3 \mathrm{~Hz}, \mathrm{C}_{\text {aro }}\right), 134.63\left(\mathrm{~m}, \mathrm{C}_{\text {aro }}\right), 134.14\left(\mathrm{C}_{\text {aro }}\right), 133.98\left(\mathrm{C}_{\text {aro }}\right), 132.79(\mathrm{dd}, J=8.2,25.8 \mathrm{~Hz}$, $\left.\mathrm{C}_{\text {aro }}\right), 131.38$ ( $\left.\mathrm{C}_{\text {aro }}\right), 131.33$ ( $\left.\mathrm{C}_{\text {aro }}\right), 131.28$ ( $\left.\mathrm{C}_{\text {aro }}\right), 130.41$ (d, J = $\left.3.5 \mathrm{~Hz}, \mathrm{C}_{\text {aro }}\right), 129.83$ (d, J = 3.7 Hz, C aro), 129.74 ( $\left.\mathrm{C}_{\text {aro }}\right), 129.17$ (d, $\left.J=7.2 \mathrm{~Hz}, \mathrm{C}_{\text {aro }}\right), 114.52\left(\mathrm{~d}, \mathrm{~J}=88.8 \mathrm{~Hz}, \mathrm{C}_{\text {aro }}\right), 30.59\left(\mathrm{dd}, J=49.3,24.7 \mathrm{~Hz}, \mathrm{CH}_{2}\right), 22.01\left(\mathrm{CH}_{3}\right) ;{ }^{31} \mathrm{P}\left\{{ }^{1} \mathrm{H}\right\} \mathrm{NMR}(202 \mathrm{MHz}$, Methylene Chloride- $\left.d_{2}\right) \delta 22.08(\mathrm{~s}),-15.62(\mathrm{~s}) ; \mathrm{IR}\left(\mathrm{cm}^{-1}\right): 3403,2867,1594,1433,1399,11312,1190,1158,1107,802,773$, 746, 721, 697, 656, 524, 498, 473, 448, 436; HR-MS (ESI): $\mathrm{m} / \mathrm{z}$ calcd for $\mathrm{C}_{40} \mathrm{H}_{37} \mathrm{P}_{2}$ [M-Br] ${ }^{+}: 579.23650$ Da; Found: 579.23605 Da.

[(2-diphenylphosphanyl)phenyl]methyltri(p-fluorophenyl) phosphonium bromide (5c)

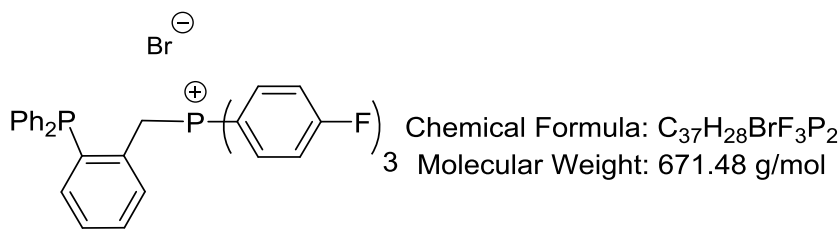

Stopped after 48 hours of reaction. Yield $=82 \%, \mathrm{~m}=0.27 \mathrm{~g}, \mathrm{n}=0.41 \mathrm{mmol}$; white solid, $\mathrm{Mp}: 134{ }^{\circ} \mathrm{C}(\mathrm{dec}) .{ }^{1} \mathrm{H}$ NMR (500 $\mathrm{MHz}$, Methylene Chloride- $\left.d_{2}\right) \delta 7.71$ (ddd, $\left.J=11.8,8.6,4.9 \mathrm{~Hz}, 6 \mathrm{H}, \mathrm{H}_{\text {aro }}\right), 7.57-7.52\left(\mathrm{~m}, 1 \mathrm{H}, \mathrm{H}_{\text {aro }}\right), 7.36-7.23\left(\mathrm{~m}, 14 \mathrm{H}, \mathrm{H}_{\text {aro }}\right)$, 6.92 - $6.82\left(\mathrm{~m}, 5 \mathrm{H}, \mathrm{H}_{\text {aro }}\right), 5.63\left(\mathrm{~d}, J=14.2 \mathrm{~Hz}, 2 \mathrm{H}, \mathrm{CH}_{2}\right) ;{ }^{13} \mathrm{C}\left\{{ }^{1} \mathrm{H}\right\} \mathrm{NMR}\left(75 \mathrm{MHz}\right.$, Methylene chloride- $\left.d_{2}\right) \delta 167.0(\mathrm{dd}, J=260.5$, $\left.3.9 \mathrm{~Hz}, \mathrm{C}_{\text {aro }}\right), 138.2\left(\mathrm{dd}, J=12.7,7.2 \mathrm{~Hz}, \mathrm{C}_{\text {aro }}\right), 137.5$ (t, J $\left.=10.9 \mathrm{~Hz}, \mathrm{C}_{\text {aro }}\right), 135.0$ (d, J = 3.6 Hz, $\mathrm{C}_{\text {aro }}$ ), $134.2\left(\mathrm{~d}, J=7.2 \mathrm{~Hz}, \mathrm{C}_{\text {aro }}\right.$ ), 
$133.5\left(\mathrm{~d}, J=19.9 \mathrm{~Hz}, \mathrm{C}_{\text {aro }}\right), 132.1\left(\mathrm{dd}, J=27.1,7.2 \mathrm{~Hz}, \mathrm{C}_{\text {aro }}\right), 131.6\left(\mathrm{t}, J=3.6 \mathrm{~Hz}, \mathrm{C}_{\text {aro }}\right), 130.2\left(\mathrm{~d}, J=3.6 \mathrm{~Hz}, \mathrm{C}_{\text {aro }}\right), 129.5(\mathrm{~d}, J=$ $\left.3.6 \mathrm{~Hz}, \mathrm{C}_{\text {aro }}\right), 129.4\left(\mathrm{C}_{\mathrm{aro}}\right), 128.8\left(\mathrm{~d}, J=7.2 \mathrm{~Hz}, \mathrm{C}_{\text {aro }}\right), 118.0$ (dd, J=22.1, $\left.13.6 \mathrm{~Hz}, \mathrm{C}_{\text {aro }}\right), 113.4$ (dd, J = 90.1, 3.4 Hz, $\left.\mathrm{C}_{\text {aro }}\right), 30.0$ (dd, $\left.J=68.0,23.4 \mathrm{~Hz}, \mathrm{CH}_{2}\right) ;{ }^{31} \mathrm{P}\left\{{ }^{1} \mathrm{H}\right\}$ NMR $\left(202 \mathrm{MHz}\right.$, Methylene Chloride- $\left.d_{2}\right) \delta 20.72(\mathrm{~s}),-17.24(\mathrm{~s}) ; \mathrm{IR}\left(\mathrm{cm}^{-1}\right): 3053,2973$, $1589,1498,1434,1399,1310,1239,1164,1108,1010,828,778,746,697 ; \mathrm{HR}-\mathrm{MS}$ (ESI): $\mathrm{m} / \mathrm{z}$ calcd for $\mathrm{C}_{37} \mathrm{H}_{28} \mathrm{~F}_{3} \mathrm{P}_{2}[\mathrm{M}-$ $\mathrm{Br}^{+}:$591.1613 Da; Found: 591.1617 Da.

[(2-diphenylphosphanyl)phenyl]methyltributylphosphonium bromide (5d)

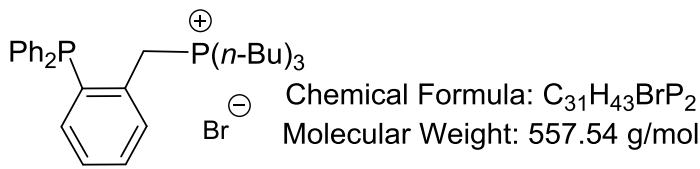

Stopped after 24 hours of reaction. Yield $=67 \%, m=0.19 \mathrm{~g}, \mathrm{n}=0.33 \mathrm{mmol}$; yellow visquous solid.

${ }^{1} \mathrm{H}$ NMR $\left(500 \mathrm{MHz}\right.$, Methylene Chloride- $\left.d_{2}\right) \delta 7.80-7.75\left(\mathrm{~m}, 1 \mathrm{H}, \mathrm{H}_{\mathrm{aro}}\right), 7.47-7.34\left(\mathrm{~m}, 7 \mathrm{H}, \mathrm{H}_{\mathrm{aro}}\right), 7.31-7.27\left(\mathrm{~m}, 1 \mathrm{H}, \mathrm{H}_{\mathrm{aro}}\right)$, $7.26-7.21\left(\mathrm{~m}, 4 \mathrm{H}, \mathrm{H}_{\text {aro }}\right), 7.02-6.96\left(\mathrm{~m}, 1 \mathrm{H}, \mathrm{H}_{\text {aro }}\right), 4.30\left(\mathrm{~d}, \mathrm{~J}=15.4 \mathrm{~Hz}, 2 \mathrm{H}, \mathrm{CH}_{2}\right), 2.55-2.43\left(\mathrm{~m}, 6 \mathrm{H}, \mathrm{PCH}_{2}\right), 1.50-1.36(\mathrm{~m}$, $\left.\left.12 \mathrm{H}, \mathrm{CH}_{2} \mathrm{CH}_{2}\right), 0.93\left(\mathrm{t}, J=6.8 \mathrm{~Hz}, 9 \mathrm{H}, \mathrm{CH}_{3}\right) ;{ }^{13} \mathrm{C}^{1}{ }^{1} \mathrm{H}\right\} \mathrm{NMR}\left(75 \mathrm{MHz}\right.$, Methylene chloride- $\left.d_{2}\right) \delta 136.8\left(\mathrm{dd}, J=13.3,5.8 \mathrm{~Hz}, \mathrm{C}_{\text {aro }}\right.$ ), $134.8\left(\mathrm{~d}, J=2.5 \mathrm{~Hz}, \mathrm{C}_{\text {aro }}\right), 134.7$ (d, J = 7.5 Hz, Caro), 133.7 (d, J = 20.2 Hz, Caro), 133.7 (d, J = 35.8 Hz, Caro), 131.9 (d, J = 4.2 Hz, $\left.\mathrm{C}_{\text {aro }}\right), 130.1$ (d, J = 3.1 Hz, C aro), 129.5 ( C aro), 129.0 (d, J = 7.7 Hz, Caro), 128.8 (d, J = 3.5 Hz, C aro), 25.2 (dd, J = 45.0, $21.4 \mathrm{~Hz}$; $\mathrm{CH}_{2}$ ), $24.0\left(\mathrm{~d}, J=14.6 \mathrm{~Hz}, \mathrm{CH}_{2}\right), 23.5\left(\mathrm{~d}, J=4.5 \mathrm{~Hz}, \mathrm{CH}_{2}\right), 19.3\left(\mathrm{dd}, J=3.5,45.5 \mathrm{~Hz}, \mathrm{CH}_{2}\right), 13.2\left(\mathrm{CH}_{3}\right) ;{ }^{31} \mathrm{P}\left\{{ }^{1} \mathrm{H}\right\} \mathrm{NMR}(202 \mathrm{MHz}$, Methylene Chloride- $\left.d_{2}\right) \delta 32.60(\mathrm{~s}),-14.57(\mathrm{~s}) ; \mathrm{IR}\left(\mathrm{cm}^{-1}\right)$ 2959, 2931, 2871, 1621, 1586, 1464, 1434, 1403, 1381, 1344, 1234, 1186, 1093, 1000, 968, 909, 746, 697; HR-MS (ESI): m/z calcd for $\mathrm{C}_{31} \mathrm{H}_{43} \mathrm{P}_{2}$ [M-Br] $]^{+}: 477.2835 \mathrm{Da}$; Found: 477.2812 Da.

[(2-diphenylphosphanyl)phenyl]methyldiphenylferrocenyl phosphonium bromide (5e)

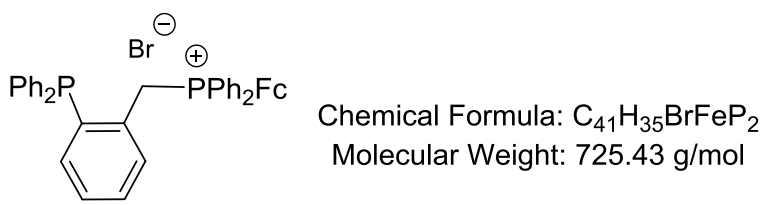

Stopped after 48 hours of reaction. Yield $=90 \%, \mathrm{~m}=0.33 \mathrm{~g}, \mathrm{n}=0.45 \mathrm{mmol}$; orange solid, $\mathrm{Mp}: 130{ }^{\circ} \mathrm{C}$ (dec). ${ }^{1} \mathrm{H}$ NMR (500 $\mathrm{MHz}$, Methylene Chloride- $\left.d_{2}\right) \delta 7.85-7.82\left(\mathrm{~m}, 2 \mathrm{H}, \mathrm{H}_{\text {aro }}\right), 7.68-7.62\left(\mathrm{~m}, 8 \mathrm{H}, \mathrm{H}_{\text {aro }}\right), 7.49-7.24\left(\mathrm{~m}, 9 \mathrm{H}, \mathrm{H}_{\text {aro }}\right), 7.02(\mathrm{t}, J=7.5 \mathrm{~Hz}$, $\left.4 \mathrm{H}, \mathrm{H}_{\text {aro }}\right), 6.78-6.76\left(\mathrm{~m}, 1 \mathrm{H}, \mathrm{H}_{\text {aro }}\right), 5.07\left(\mathrm{~d}, \mathrm{~J}=13.8 \mathrm{~Hz}, 2 \mathrm{H}, \mathrm{CH}_{2}\right), 4.92(\mathrm{~s}, 2 \mathrm{H}, \mathrm{Cp}), 4.55(\mathrm{~s}, 2 \mathrm{H}, \mathrm{Cp}), 4.39(\mathrm{~s}, 5 \mathrm{H}, \mathrm{Cp}) ;{ }^{13} \mathrm{C}\left\{{ }^{1} \mathrm{H}\right\}$ $\operatorname{NMR}\left(75 \mathrm{MHz}\right.$, Methylene chloride- $\left.d_{2}\right) \delta 137.8\left(\mathrm{dd}, J=12.7,6.1 \mathrm{~Hz}, \mathrm{C}_{\text {aro }}\right), 134.8\left(\mathrm{~d}, J=2.8 \mathrm{~Hz}, \mathrm{C}_{\text {aro }}\right), 134.3\left(\mathrm{C}_{\text {aro }}\right), 134.2\left(\mathrm{C}_{\text {aro }}\right)$, $134.1\left(\mathrm{~d}, J=9.9 \mathrm{~Hz}, \mathrm{C}_{\text {aro }}\right), 133.7$ (d, J = $\left.19.9 \mathrm{~Hz}, \mathrm{C}_{\text {aro }}\right), 132.7$ (dd, J = 24.8, $\left.7.8 \mathrm{~Hz}, \mathrm{C}_{\text {aro }}\right), 131.5$ (t, J = 4.4 Hz, Caro), 129.8 (d, J = $\left.3.5 \mathrm{~Hz}, \mathrm{C}_{\text {aro }}\right), 129.7$ (d, J = $\left.12.6 \mathrm{~Hz}, \mathrm{C}_{\text {aro }}\right), 129.4\left(\mathrm{C}_{\text {aro }}\right), 129.1$ (d, J = 3.8 Hz, Caro), 128.9 (d, J = 7.2 Hz, Caro), $119.3(\mathrm{~d}, J=87.7 \mathrm{~Hz}$, $\mathrm{C}_{\text {aro }}$ ), $74.8(\mathrm{Cp}), 74.7(\mathrm{Cp}), 73.2(\mathrm{~d}, J=3.1 \mathrm{~Hz}, \mathrm{Cp}), 73.1(\mathrm{~d}, J=3.5 \mathrm{~Hz}, \mathrm{Cp}), 70.9(\mathrm{Cp}), 60.8(\mathrm{~d}, J=100.9 \mathrm{~Hz}, \mathrm{Cp}), 29.7$ (dd, $J=$ 51.3, $\left.22.3 \mathrm{~Hz}, \mathrm{CH}_{2}\right) ;{ }^{31} \mathrm{P}\left\{{ }^{1} \mathrm{H}\right\}$ NMR $\left(202 \mathrm{MHz}\right.$, Methylene Chloride- $\mathrm{d}_{2}$ ) $\delta 26.29(\mathrm{~s}),-14.13(\mathrm{~s}) ; \mathrm{IR}\left(\mathrm{cm}^{-1}\right): 3052,2853,1587,1478$, $1434,1413,1392,1181,1107,1029,998,829,781,745,726,691 ; \mathrm{HR}-\mathrm{MS}$ (ESI): $\mathrm{m} / \mathrm{z}$ calcd for $\mathrm{C}_{41} \mathrm{H}_{35} \mathrm{FeP}_{2}[\mathrm{M}-\mathrm{Br}]^{+}: 645.1557$ Da; Found: $645.1552 \mathrm{Da}$.

\section{[(2-diphenylphosphanyl)phenyl]methyldiphenylmethyl phosphonium bromide (5f)}

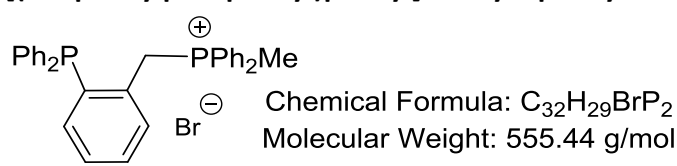

Stopped after 24 hours of reaction. Yield $=80 \%, \mathrm{~m}=0.22 \mathrm{~g}, \mathrm{n}=0.4 \mathrm{mmol}$; white solid, $\mathrm{Mp}: 122^{\circ} \mathrm{C}(\mathrm{dec}) .{ }^{1} \mathrm{H} \mathrm{NMR}(500 \mathrm{MHz}$, Methylene Chloride $\left.-d_{2}\right) \delta 7.86-7.78\left(\mathrm{~m}, 6 \mathrm{H}, \mathrm{H}_{\text {aro }}\right), 7.68-7.62\left(\mathrm{~m}, 5 \mathrm{H}, \mathrm{H}_{\mathrm{aro}}\right), 7.41-7.30\left(\mathrm{~m}, 8 \mathrm{H}, \mathrm{H}_{\text {aro }}\right), 7.05-6.92\left(\mathrm{~m}, 5 \mathrm{H}, \mathrm{H}_{\text {aro }}\right)$, $\left.5.10\left(\mathrm{dd}, J=15.7,1.2 \mathrm{~Hz}, 2 \mathrm{H}, \mathrm{CH}_{2}\right), 2.83\left(\mathrm{~d}, J=13.4 \mathrm{~Hz}, 3 \mathrm{H}, \mathrm{CH}_{3}\right) ;{ }^{13} \mathrm{C}^{1} \mathrm{H}\right\}$ NMR $\left(126 \mathrm{MHz}\right.$, Methylene Chloride- $\left.d_{2}\right) \delta 137.6$ (dd, $\left.J=13.8,6.9 \mathrm{~Hz}, \mathrm{C}_{\text {aro }}\right), 135.0\left(\mathrm{~d}, J=2.6 \mathrm{~Hz}, \mathrm{C}_{\text {aro }}\right), 134.8\left(\mathrm{C}_{\mathrm{aro}}\right), 134.8\left(\mathrm{~d}, J=2.5 \mathrm{~Hz}, \mathrm{C}_{\text {aro }}\right), 133.6\left(\mathrm{~d}, J=20.2 \mathrm{~Hz}, \mathrm{C}_{\text {aro }}\right), 133.1$ (d, J = 10.4 Hz, Caro), 132.6 (dd, J = 26.7, $\left.8.5 \mathrm{~Hz}, \mathrm{C}_{\text {aro }}\right), 131.6$ (t, J = 4.6 Hz, Caro), 130.0 (d, J = 3.7 Hz, Caro), 129.9 (d, J=12.5 Hz, $\left.\mathrm{C}_{\text {aro }}\right), 129.2\left(\mathrm{C}_{\text {aro }}\right), 129.0\left(\mathrm{~d}, J=3.6 \mathrm{~Hz}, \mathrm{C}_{\text {aro }}\right), 128.8\left(\mathrm{~d}, J=7.3 \mathrm{~Hz}, \mathrm{C}_{\text {aro }}\right), 118.9\left(\mathrm{~d}, J=84.3 \mathrm{~Hz}, \mathrm{C}_{\text {aro }}\right), 28.7$ (dd, $J=47.8,23.4 \mathrm{~Hz}$, $\left.\mathrm{CH}_{2}\right), 8.3\left(\mathrm{dd}, J=56.1,3.4 \mathrm{~Hz}, \mathrm{CH}_{3}\right)$. One carbon signal is not seen. ${ }^{31} \mathrm{P}\left\{{ }^{1} \mathrm{H}\right\} \mathrm{NMR}\left(202 \mathrm{MHz}\right.$, Methylene Chloride- $\left.d_{2}\right) \delta 21.75$ (s), $-15.53(\mathrm{~s})$; IR ( $\left.\mathrm{cm}^{-1}\right)$ : 3053, 2882, 1618, 1588, 1476, 1434, 1186, 1161, 1116, 1027, 997, 900, 841, 743, 689; HR-MS (ESI): $\mathrm{m} / \mathrm{z}$ calcd for $\mathrm{C}_{32} \mathrm{H}_{29} \mathrm{P}_{2}[\mathrm{M}-\mathrm{Br}]^{+}$: 475.1739 Da; Found : $475.1733 \mathrm{Da}$.

\section{General synthesis of the phosphonium phosphine gold complexes la-f}

To a solution of phosphonium phosphine $5 \mathrm{a}-\mathrm{f}(0.1 \mathrm{mmol})$ in DCM $(4 \mathrm{~mL})$, bromo(tetrahydrothiophene)Au(I) $(0.1 \mathrm{mmol})$ was added under argon at RT. The reaction was stirred until completion, as determined by ${ }^{31} \mathrm{P}$ NMR (one hour). Then the 
resulting mixture was concentrated and the product was precipitated using pentane and washed twice with a mixture of pentane/DCM 10: 1.

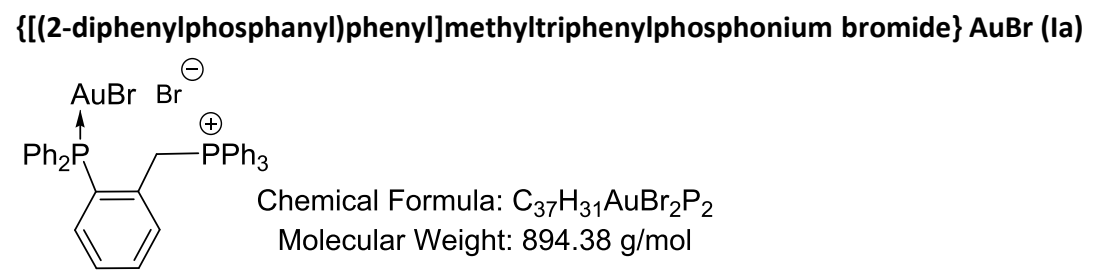

Yield $=80 \%, \mathrm{~m}=0.07 \mathrm{~g}, \mathrm{n}=0.08 \mathrm{mmol}$; white solid, $\mathrm{Mp}: 150{ }^{\circ} \mathrm{C}(\mathrm{dec}) .{ }^{1} \mathrm{H}$ NMR $\left(500 \mathrm{MHz}\right.$, Methylene Chloride- $\left.\mathrm{d}_{2}\right) \delta 7.90-$ $7.86\left(\mathrm{~m}, 3 \mathrm{H}, \mathrm{H}_{\mathrm{aro}}\right), 7.70-7.64\left(\mathrm{~m}, 6 \mathrm{H}, \mathrm{H}_{\mathrm{aro}}\right), 7.63-7.55\left(\mathrm{~m}, 8 \mathrm{H}, \mathrm{H}_{\mathrm{aro}}\right), 7.50\left(\mathrm{bs}, 4 \mathrm{H}, \mathrm{H}_{\text {aro }}\right), 7.41\left(\mathrm{~s}, 3 \mathrm{H}, \mathrm{H}_{\text {aro }}\right), 7.33$ (bs, $\left.3 \mathrm{H}, \mathrm{H}_{\text {aro }}\right)$, 7.28 - $7.23\left(\mathrm{~m}, 1 \mathrm{H}, \mathrm{H}_{\text {aro }}\right), 6.93-6.86\left(\mathrm{~m}, 1 \mathrm{H}, \mathrm{H}_{\text {aro }}\right), 5.55-5.43\left(\mathrm{~m}, 2 \mathrm{H}, \mathrm{CH}_{2}\right) .{ }^{13} \mathrm{C}\left\{{ }^{1} \mathrm{H}\right\} \mathrm{NMR}\left(151 \mathrm{MHz}\right.$, Methylene Chloride- $\left.d_{2}\right) \delta$ $135.94\left(\mathrm{~d}, J=3.0 \mathrm{~Hz}, \mathrm{C}_{\text {aro }}\right), 135.73\left(\mathrm{~d}, J=6.7 \mathrm{~Hz}, \mathrm{C}_{\text {aro }}\right), 135.20\left(\mathrm{C}_{\text {aro }}\right), 135.13\left(\mathrm{C}_{\text {aro }}\right), 134.78$ (d, J = $\left.14.5 \mathrm{~Hz}, \mathrm{C}_{\text {aro }}\right), 132.89(\mathrm{~m}$,

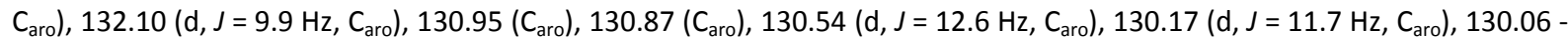
$129.98(\mathrm{~m}), 129.12\left(\mathrm{~d}, J=12.3 \mathrm{~Hz}, \mathrm{C}_{\text {aro }}\right), 117.50\left(\mathrm{~d}, J=86.3 \mathrm{~Hz}, \mathrm{C}_{\text {aro }}\right), 29.79\left(\mathrm{dd}, J=48.9,13.5 \mathrm{~Hz}, \mathrm{CH}_{2}\right) .{ }^{31} \mathrm{P}\left\{{ }^{1} \mathrm{H}\right\} \mathrm{NMR}(202$ $\mathrm{MHz}$, Methylene Chloride- $d_{2}$ ) $\delta 25.98$ (s), 22.66 (bs); IR ( $\mathrm{cm}^{-1}$ ): 3341, 3051, 1585, 1478, 1434, 1161, 1098, 995, 822, 780, 744, 687, 546, 494; m/z calcd for $\mathrm{C}_{37} \mathrm{H}_{31} \mathrm{AuBrP}_{2}[\mathrm{M}-\mathrm{Br}]^{+}:$: $13.0744 \mathrm{Da}$; Found: 813.0739 Da. Elemental Analysis calculated for $\mathrm{C}_{37} \mathrm{H}_{31} \mathrm{AuBr}_{2} \mathrm{P}_{2}$ : C\% 49.69, H\% 3.49; Obtained: C\% 49.82, H\% 3.51 .

$\{[(2$-diphenylphosphanyl)phenyl]methyltri(p-tolyl)phosphonium bromide\} AuBr (Ib)

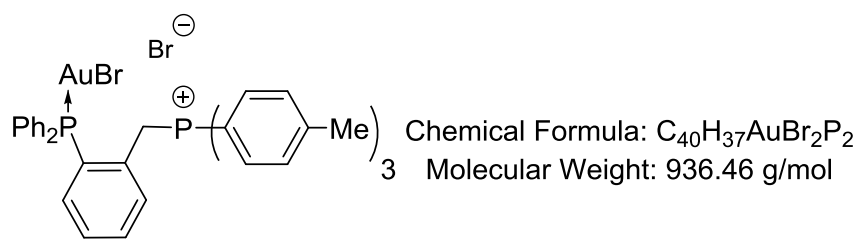

Yield $=94 \%, \mathrm{~m}=0.088 \mathrm{~g}, \mathrm{n}=0.094 \mathrm{mmol}$; white solid, $\mathrm{Mp}>250{ }^{\circ} \mathrm{C} .{ }^{1} \mathrm{H}$ NMR $\left(500 \mathrm{MHz}\right.$, Methylene Chloride- $\left.d_{2}\right) \delta 7.57$ (bs, $\left.3 \mathrm{H}, \mathrm{H}_{\text {aro }}\right), 7.54-7.28\left(\mathrm{~m}, 21 \mathrm{H}, \mathrm{H}_{\text {aro }}\right), 7.22-7.16\left(\mathrm{~m}, 1 \mathrm{H}, \mathrm{H}_{\text {aro }}\right), 6.95-6.87\left(\mathrm{~m}, 1 \mathrm{H}, \mathrm{H}_{\text {aro }}\right), 5.25-5.17\left(\mathrm{~m}, 2 \mathrm{H}, \mathrm{CH}_{2}\right), 2.51(\mathrm{~s}, 9 \mathrm{H}$, $\left.\mathrm{CH}_{3}\right) ;{ }^{13} \mathrm{C}\left\{{ }^{1} \mathrm{H}\right\}$ NMR $\left(151 \mathrm{MHz}\right.$, Methylene Chloride- $\left.d_{2}\right) \delta 147.51\left(\mathrm{~d}, J=2.9 \mathrm{~Hz}, \mathrm{C}_{\text {aro }}\right), 135.70\left(\mathrm{~d}, J=6.5 \mathrm{~Hz}, \mathrm{C}_{\text {aro }}\right), 134.86(\mathrm{~d}, J=$ $\left.10.5 \mathrm{~Hz}, \mathrm{C}_{\text {aro }}\right), 134.76\left(\mathrm{~d}, J=14.4 \mathrm{~Hz}, \mathrm{C}_{\text {aro }}\right), 132.95\left(\mathrm{dd}, J=11.1,6.8 \mathrm{~Hz}, \mathrm{C}_{\text {aro }}\right), 132.82-132.53\left(\mathrm{~m}, \mathrm{C}_{\text {aro }}\right), 131.63\left(\mathrm{C}_{\text {aro }}\right), 131.54$ $\left(C_{\text {aro }}\right), 130.11$ (d, J = $11.7 \mathrm{~Hz}, \mathrm{C}_{\text {aro }}$ ), 129.95 (d, J = 3.2 Hz, $\mathrm{C}_{\text {aro }}$ ), 129.90 (d, J = 3.2 Hz, $\mathrm{C}_{\text {aro }}$ ), 114.25 (d, J = 89.0 Hz, $\mathrm{C}_{\text {aro }}$ ), 30.22 $\left(\mathrm{dd}, J=50.5,13.6 \mathrm{~Hz}, \mathrm{CH}_{2}\right), 22.10\left(\mathrm{CH}_{3}\right) ;{ }^{31} \mathrm{P}\left\{{ }^{1} \mathrm{H}\right\} \mathrm{NMR}\left(202 \mathrm{MHz}\right.$, Methylene Chloride- $\left.d_{2}\right) \delta 26.07(\mathrm{~s}), 21.76(\mathrm{~s}) ; \mathrm{IR}\left(\mathrm{cm}^{-1}\right)$ : $3353,2917,1596,1498,1476,1434,1399,1190,1099,801,749,692,652,541,499 ; \mathrm{m} / \mathrm{z}$ calcd for $\mathrm{C}_{40} \mathrm{H}_{37} \mathrm{AuBrP}_{2}[\mathrm{M}-$ $\mathrm{Br}]^{+}$: 855.1214 Da; Found: 855.1208 Da. Elemental Analysis calculated for $\mathrm{C}_{40} \mathrm{H}_{37} \mathrm{AuBr}_{2} \mathrm{P}_{2}$ : C\% 51.30, H\% 3.98; Obtained: C\% $51.04, \mathrm{H} \%$ 4.36.

$\{[(2-$ diphenylphosphanyl)phenyl]methyltri(p-fluorophenyl) phosphonium bromide\}AuBr (Ic)

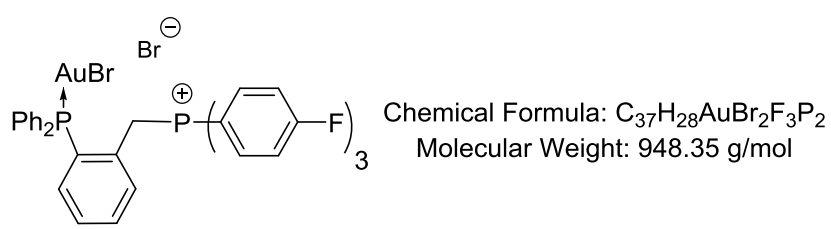

Yield $=64 \%, \mathrm{~m}=0.061 \mathrm{~g}, \mathrm{n}=0.064 \mathrm{mmol}$; white solid, $\mathrm{Mp}: 140{ }^{\circ} \mathrm{C} .{ }^{1} \mathrm{H}$ NMR $\left(600 \mathrm{MHz}\right.$, Methylene Chloride- $\left.d_{2}\right) \delta 7.69-7.59$ $\left(\mathrm{m}, 8 \mathrm{H}, \mathrm{H}_{\text {aro }}\right), 7.58-7.50\left(\mathrm{~m}, 4 \mathrm{H}, \mathrm{H}_{\text {aro }}\right), 7.49\left(\mathrm{t}, J=7.6 \mathrm{~Hz}, 1 \mathrm{H}, \mathrm{H}_{\text {aro }}\right), 7.48-7.32\left(\mathrm{~m}, 11 \mathrm{H}, \mathrm{H}_{\text {aro }}\right), 7.23\left(\mathrm{t}, J=6.4 \mathrm{~Hz}, 1 \mathrm{H}, \mathrm{H}_{\text {aro }}\right), 6.92$ $\left(\mathrm{dd}, J=12.4,7.8 \mathrm{~Hz}, 1 \mathrm{H}, \mathrm{H}_{\text {aro }}\right), 5.52\left(\mathrm{~d}, J=14.8 \mathrm{~Hz}, 2 \mathrm{H}, \mathrm{CH}_{2}\right) .{ }^{13} \mathrm{C}\left\{{ }^{1} \mathrm{H}\right\} \mathrm{NMR}\left(151 \mathrm{MHz}\right.$, Methylene Chloride- $\left.d_{2}\right) \delta 167.63(\mathrm{dd}, J=$ $\left.261.2,3.0 \mathrm{~Hz}, \mathrm{C}_{\text {aro }}\right), 138.15$ (d, J = 10.2 Hz, C aro), 138.07 (d, J = $\left.10.2 \mathrm{~Hz}, \mathrm{C}_{\text {aro }}\right), 135.92$ (d, J = 7.3 Hz, $\left.\mathrm{C}_{\text {aro }}\right), 134.86(\mathrm{~d}, J=14.3 \mathrm{~Hz}$, $\left.\mathrm{C}_{\text {aro }}\right), 133.26\left(\mathrm{~m}, \mathrm{C}_{\text {aro }}\right), 133.02\left(\mathrm{C}_{\text {aro }}\right), 132.06\left(\mathrm{~d}, J=9.1 \mathrm{~Hz}, \mathrm{C}_{\text {aro }}\right), 130.36\left(\mathrm{~d}, J=12.2 \mathrm{~Hz}, \mathrm{C}_{\text {aro }}\right), 127.33\left(\mathrm{dd}, J=63.3,3.5 \mathrm{~Hz}, \mathrm{C}_{\text {aro }}\right)$,

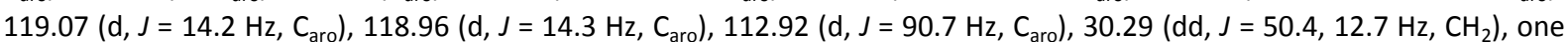
carbon is not seen. ${ }^{31} \mathrm{P}\left\{{ }^{1} \mathrm{H}\right\}$ NMR $\left(243 \mathrm{MHz}\right.$, Methylene Chloride- $\left.d_{2}\right) \delta 26.07(\mathrm{~s}), 21.71(\mathrm{~s}) ; \mathrm{IR}\left(\mathrm{cm}^{-1}\right): 3054,1588,1497,1435$, $1398,1308,1241,1162,1099,1009,828,773,747,691,661,542,515,482,443 ; \mathrm{m} / \mathrm{z}$ calcd for $\mathrm{C}_{37} \mathrm{H}_{28} \mathrm{AuBrF}_{3} \mathrm{P}_{2}[\mathrm{M}-$ $\mathrm{Br}]^{+}$: 867.0462 Da; Found: 867.0464 Da. Elemental Analysis calculated for $\mathrm{C}_{37} \mathrm{H}_{28} \mathrm{AuBr}_{2} \mathrm{~F}_{3} \mathrm{P}_{2}$ : C\% 46.86; H\% 2.98; Obtained: C\% 47.09, H\% 3.23.

\{[(2-diphenylphosphany)Iphenyl]methyltributylphosphonium bromide]\}AuBr (Id) 


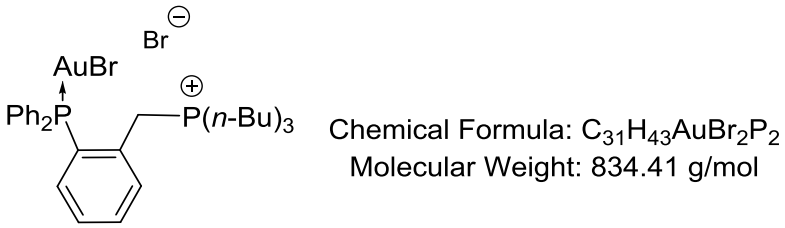

Yield $=80 \%, \mathrm{~m}=0.067 \mathrm{~g}, \mathrm{n}=0.08 \mathrm{mmol}$, white solid, Mp: $152{ }^{\circ} \mathrm{C} .{ }^{1} \mathrm{H}$ NMR $\left(500 \mathrm{MHz}\right.$, Methylene Chloride- $\left.d_{2}\right) \delta 7.90(\mathrm{t}, J=$ $\left.6.6 \mathrm{~Hz}, 1 \mathrm{H}, \mathrm{H}_{\text {aro }}\right), 7.70\left(\mathrm{t}, J=7.6 \mathrm{~Hz}, 1 \mathrm{H}, \mathrm{H}_{\text {aro }}\right), 7.67-7.61\left(\mathrm{~m}, 2 \mathrm{H}, \mathrm{H}_{\text {aro }}\right), 7.60-7.48\left(\mathrm{~m}, 8 \mathrm{H}, \mathrm{H}_{\text {aro }}\right), 7.40\left(\mathrm{t}, J=7.7 \mathrm{~Hz}, 1 \mathrm{H}, \mathrm{H}_{\text {aro }}\right)$, 6.95 (ddd, $\left.J=12.5,7.8,1.1 \mathrm{~Hz}, 1 \mathrm{H}, \mathrm{H}_{\mathrm{aro}}\right), 4.58\left(\mathrm{~d}, J=15.5 \mathrm{~Hz}, 2 \mathrm{H}, \mathrm{CH}_{2}\right), 2.62-2.51(\mathrm{~m}, 6 \mathrm{H}), 1.52-1.27(\mathrm{~m}, 12 \mathrm{H}), 0.93(\mathrm{t}, J=$ $6.9 \mathrm{~Hz}, 9 \mathrm{H}) ;{ }^{13} \mathrm{C}\left\{{ }^{1} \mathrm{H}\right\}$ NMR (151 MHz, Methylene Chloride- $\left.d_{2}\right) \delta 135.60\left(\mathrm{~d}, J=7.6 \mathrm{~Hz}, \mathrm{C}_{\text {aro }}\right), 134.85\left(\mathrm{~d}, J=14.0 \mathrm{~Hz}, \mathrm{C}_{\text {aro }}\right), 133.97$ - $133.65\left(\mathrm{~m}, \mathrm{C}_{\text {aro }}\right), 133.42\left(\mathrm{t}, J=3.5 \mathrm{~Hz}, \mathrm{C}_{\text {aro }}\right), 133.30$ (d, J = 2.6 Hz, $\mathrm{C}_{\text {aro }}$ ), 132.14 (d, J = $\left.10.0 \mathrm{~Hz}, \mathrm{C}_{\text {aro }}\right), 130.32(\mathrm{~d}, J=12.2 \mathrm{~Hz}$, $\left.\mathrm{C}_{\text {aro }}\right), 129.36\left(\mathrm{dd}, J=9.5,2.8 \mathrm{~Hz}, \mathrm{C}_{\text {aro }}\right), 127.94\left(\mathrm{dd}, J=57.9,6.6 \mathrm{~Hz}, \mathrm{C}_{\text {aro }}\right), 127.63$ (d, J = 63.1 Hz, $\left.\mathrm{C}_{\text {aro }}\right), 26.33$ (dd, $J=45.5,12.1$ $\left.\mathrm{Hz}, \mathrm{CH}_{2}\right), 24.37\left(\mathrm{CH}_{2}\right), 24.30\left(\mathrm{~d}, J=11.7 \mathrm{~Hz}, \mathrm{CH}_{2}\right), 20.49\left(\mathrm{~d}, J=45.5 \mathrm{~Hz}, \mathrm{CH}_{2}\right), 13.66\left(\mathrm{CH}_{3}\right) .{ }^{31} \mathrm{P}\left\{{ }^{1} \mathrm{H}\right\} \mathrm{NMR}(202 \mathrm{MHz}$, Methylene Chloride- $\left.d_{2}\right) \delta 33.43(\mathrm{~s}), 26.91$ (s); IR ( $\left.\mathrm{cm}^{-1}\right): 2866,1463,1434,1309,1193,1119,911,746,691,541,500,474 ; \mathrm{m} / \mathrm{z}$ calcd for $\mathrm{C}_{31} \mathrm{H}_{43} \mathrm{AuBrP}{ }_{2}[\mathrm{M}-\mathrm{Br}]^{+}: 753.16834 \mathrm{Da}$; Found : $753.16567 \mathrm{Da}$. Elemental Analysis calculated for $\mathrm{C}_{31} \mathrm{H}_{43} \mathrm{AuBr}_{2} \mathrm{P}_{2}: \mathrm{C} \%$ 44.62, $\mathrm{H} \%$ 5.19; Obtained: C\% 44.98, H\% 5.35 .

\{[(2-diphenylphosphanyl)phenyl]methyldiphenylferrocenyl phosphonium bromide\}AuBr (le)

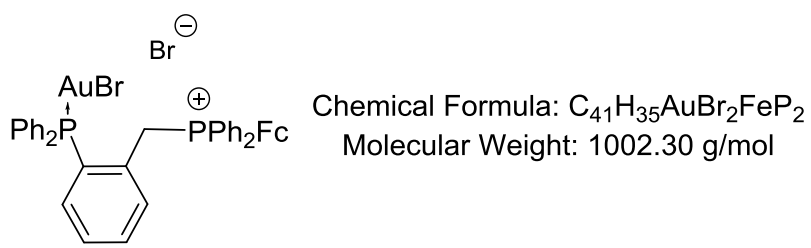

The product was recrystallized by vapor diffusion of cyclohexane in DCM.

Yield $=78 \%, \mathrm{~m}=0.078 \mathrm{~g}, \mathrm{n}=0.078 \mathrm{mmol}$; orange solid, $\mathrm{Mp}: 190^{\circ} \mathrm{C} .{ }^{1} \mathrm{H}$ NMR $\left(600 \mathrm{MHz}\right.$, Methylene Chloride- $\left.d_{2}\right) \delta 7.81$ (bs, $\left.2 \mathrm{H}, \mathrm{H}_{\text {aro }}\right), 7.75-7.67\left(\mathrm{~m}, 4 \mathrm{H}, \mathrm{H}_{\text {aro }}\right), 7.66-7.50\left(\mathrm{~m}, 15 \mathrm{H}, \mathrm{H}_{\text {aro }}\right), 7.49$ (bs, $\left.1 \mathrm{H}, \mathrm{H}_{\text {aro }}\right), 7.34$ (bs, $\left.1 \mathrm{H}, \mathrm{H}_{\text {aro }}\right), 6.77$ (dd, J = 12.9, 7.0 Hz, $\left.1 \mathrm{H}, \mathrm{H}_{\text {aro }}\right), 5.19\left(\mathrm{~d}, J=15.3 \mathrm{~Hz}, 2 \mathrm{H}, \mathrm{CH}_{2}\right), 4.82(\mathrm{~s}, 2 \mathrm{H}, \mathrm{Cp}), 4.44(\mathrm{~s}, 2 \mathrm{H}, \mathrm{Cp}), 4.27(\mathrm{~s}, 5 \mathrm{H}, \mathrm{Cp}) ;{ }^{13} \mathrm{C}\left\{{ }^{1} \mathrm{H}\right\} \mathrm{NMR}(151 \mathrm{MHz}$, Methylene Chloride $\left.-d_{2}\right) \delta 135.47\left(\mathrm{~d}, J=3.0 \mathrm{~Hz}, \mathrm{C}_{\text {aro }}\right), 135.23\left(\mathrm{~d}, J=6.4 \mathrm{~Hz}, \mathrm{C}_{\text {aro }}\right), 135.18$ (d, J = $\left.14.2 \mathrm{~Hz}, \mathrm{C}_{\text {aro }}\right), 134.81$ (d, J = 10.2 Hz, $\mathrm{C}_{\text {aro }}$ ), $133.25\left(\mathrm{~d}, J=6.7 \mathrm{~Hz}, \mathrm{C}_{\text {aro }}\right), 133.17\left(\mathrm{~d}, J=2.6 \mathrm{~Hz}, \mathrm{C}_{\text {aro }}\right), 132.72\left(\mathrm{C}_{\text {aro }}\right), 130.60$ (d, J = $\left.12.7 \mathrm{~Hz}, \mathrm{C}_{\text {aro }}\right), 130.47\left(\mathrm{~d}, J=12.2 \mathrm{~Hz}, \mathrm{C}_{\text {aro }}\right)$, 129.59 (dd, $\left.J=9.3,2.6 \mathrm{~Hz}, \mathrm{C}_{\text {aro }}\right), 128.85\left(\mathrm{dd}, J=57.9,7.7 \mathrm{~Hz}, \mathrm{C}_{\text {aro }}\right), 127.75\left(\mathrm{~d}, J=63.0 \mathrm{~Hz}, \mathrm{C}_{\text {aro }}\right), 118.86\left(\mathrm{~d}, J=87.7 \mathrm{~Hz}, \mathrm{C}_{\text {aro }}\right)$, 75.09 (d, $J=10.7 \mathrm{~Hz}, \mathrm{Cp}$ ), 73.77 (d, $J=13.0 \mathrm{~Hz}, \mathrm{Cp}$ ), 71.39 (Cp), 60.73 (d, $J=102.8 \mathrm{~Hz}, \mathrm{Cp}$ aro), 31.06 (dd, $J=53.9,11.8 \mathrm{~Hz}$, $\left.\mathrm{CH}_{2}\right)$; one quaternary carbon signal is not seen. ${ }^{31} \mathrm{P}\left\{{ }^{1} \mathrm{H}\right\} \mathrm{NMR}\left(243 \mathrm{MHz}\right.$, Methylene Chloride- $\left.d_{2}\right) \delta 27.88(\mathrm{~s}), 26.43(\mathrm{~s}) ; \mathrm{IR}\left(\mathrm{cm}^{-}\right.$ $\left.{ }^{1}\right)$ : $3388,3054,1586,1478,1434,1180,1106,1033,996,838,781,744,726,691,598,547,469 ; \mathrm{m} / \mathrm{z}$ calcd for $\mathrm{C}_{41} \mathrm{H}_{35} \mathrm{AuBrFeP}_{2}[\mathrm{M}-\mathrm{Br}]^{+}: 921.0409 \mathrm{Da}$; Found: $921.0433 \mathrm{Da}$. Elemental Analysis calculated for $\mathrm{C}_{41} \mathrm{H}_{35} \mathrm{AuBr}_{2} \mathrm{FeP}_{2}: \mathrm{C}_{0} 49.13$, H\% 3.52; Obtained: C\% 48.92, H\% 3.52.

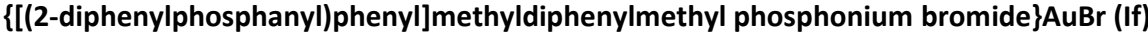

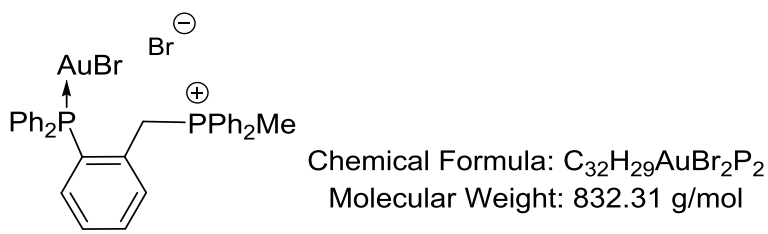

The product was recrystallized by vapor diffusion of cyclohexane in DCM. Yield $=87 \%, \mathrm{~m}=0.072 \mathrm{~g}, \mathrm{n}=0.087 \mathrm{mmol}$; white solid, $\mathrm{Mp}: 158^{\circ} \mathrm{C}$.

${ }^{1} \mathrm{H}$ NMR $\left(500 \mathrm{MHz}\right.$, Methylene Chloride- $\left.d_{2}\right) \delta 7.85-7.77\left(\mathrm{~m}, 6 \mathrm{H}, \mathrm{H}_{\text {aro }}\right), 7.68-7.62\left(\mathrm{~m}, 4 \mathrm{H}, \mathrm{H}_{\text {aro }}\right), 7.61-7.56\left(\mathrm{~m}, 2 \mathrm{H}, \mathrm{H}_{\text {aro }}\right), 7.54$ - $7.45\left(\mathrm{~m}, 6 \mathrm{H}, \mathrm{H}_{\text {aro }}\right), 7.39$ (ddd, J = 7.6, 6.1, $\left.1.8 \mathrm{~Hz}, 1 \mathrm{H}, \mathrm{H}_{\text {aro }}\right), 7.33-7.25\left(\mathrm{~m}, 4 \mathrm{H}, \mathrm{H}_{\text {aro }}\right), 6.93$ (ddd, J = 12.1, 7.8, $\left.1.3 \mathrm{~Hz}, 1 \mathrm{H}, \mathrm{H}_{\text {aro }}\right)$, $5.50\left(\mathrm{~d}, J=15.6 \mathrm{~Hz}, 2 \mathrm{H}, \mathrm{CH}_{2}\right), 2.90(\mathrm{~d}, J=13.4 \mathrm{~Hz}, 3 \mathrm{H}, \mathrm{Me}) ;{ }^{13} \mathrm{C}\left\{{ }^{1} \mathrm{H}\right\} \mathrm{NMR}\left(151 \mathrm{MHz}\right.$, Methylene Chloride- $\left.d_{2}\right) \delta 135.95(\mathrm{~d}, J=$ $\left.6.4 \mathrm{~Hz}, \mathrm{C}_{\text {aro }}\right), 135.47$ (d, J = 3.1 Hz, $\left.\mathrm{C}_{\text {aro }}\right), 134.69$ (d, J=14.1 Hz, $\left.\mathrm{C}_{\text {aro }}\right), 134.09$ (d, J = $\left.10.0 \mathrm{~Hz}, \mathrm{C}_{\text {aro }}\right), 133.44-133.59$ (m, $\mathrm{C}_{\text {aro }}$ ), $133.13\left(\mathrm{C}_{\text {aro }}\right), 132.93-132.91\left(\mathrm{~m}, \mathrm{C}_{\text {aro }}\right), 130.60$ (d, J = $\left.12.4 \mathrm{~Hz}, \mathrm{C}_{\text {aro }}\right), 130.11$ (d, J=12.1 Hz, $\mathrm{C}_{\text {aro }}$ ), 129.68 (dd, J = 9.1, 3.2 Hz, $\left.\mathrm{C}_{\text {aro }}\right), 127.83\left(\mathrm{~d}, J=61.8 \mathrm{~Hz}, \mathrm{C}_{\mathrm{aro}}\right), 118.70\left(\mathrm{~d}, J=84.5 \mathrm{~Hz}, \mathrm{C}_{\mathrm{aro}}\right), 30.10$ (dd, $J=48.7,12.9 \mathrm{~Hz}, \mathrm{CH}_{2}$ ), $9.67(\mathrm{~d}, J=55.4 \mathrm{~Hz}, \mathrm{Me})$. ${ }^{31} \mathrm{P}\left\{{ }^{1} \mathrm{H}\right\}$ NMR (202 MHz, Methylene Chloride- $\left.d_{2}\right) \delta 24.91(\mathrm{~s}), 21.80(\mathrm{~s}) ; \mathrm{IR}\left(\mathrm{cm}^{-1}\right): 3380,2824,1586,1435,1307,1189,1099$, 996, 902, 744, 689, 540, 499, 473, 452; m/z calcd for $\mathrm{C}_{32} \mathrm{H}_{29} \mathrm{AuBrP}_{2}[\mathrm{M}-\mathrm{Br}]^{+}: 751.0588 \mathrm{Da}$; Found : 751.0594 Da. Elemental Analysis calculated for $\mathrm{C}_{32} \mathrm{H}_{29} \mathrm{AuBr}_{2} \mathrm{P}_{2}$ : C\% 46.18, $\mathrm{H} \% 3.51$. 


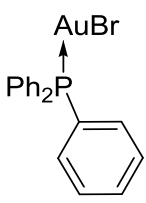

To a solution of triphenylphosphine $(26 \mathrm{mg}, 0.1 \mathrm{mmol})$ in DCM $(2 \mathrm{~mL})$, bromo(tetrahydrothiophene)Au(l) (36.5 mg, 0.1 $\mathrm{mmol}$ ) was added under argon at RT. The reaction was stirred until completion, as determined by ${ }^{31} \mathrm{P} N M R$ (one hour). Then the resulting mixture was concentrated and the product was precipitated using pentane and washed twice with a $5 \mathrm{~mL}$ of pentane to give $\mathbf{I g}$ as a white powder.

Yield $=69 \%, \mathrm{~m}=0.037 \mathrm{~g}, \mathrm{n}=0.069 \mathrm{mmol}$.

${ }^{1} \mathrm{H}$ NMR $\left(500 \mathrm{MHz}\right.$, Methylene Chloride- $\left.d_{2}\right) \delta$ 7.61-7.52 (m, 3H, $\left.\mathrm{H}_{\text {aro }}\right), 7.52-7.46\left(\mathrm{~m}, 2 \mathrm{H}, \mathrm{H}_{\text {aro }}\right),{ }^{31} \mathrm{P}\left\{{ }^{1} \mathrm{H}\right\} \mathrm{NMR}(202 \mathrm{MHz}$, Methylene Chloride- $d_{2}$ ) $\delta 35.19$ (s). Elemental Analysis calculated for $\mathrm{C}_{18} \mathrm{H}_{15} \mathrm{AuBrP}$ : C\% 40.10, H\% 2.80; Obtained: C\% 39.92, $\mathrm{H} \% 2.68$.

\section{Biological experimental procedures}

\section{Cell lines and culture conditions}

Human colon cancer (SW 480), human breast cancer (MDA-MB-231), and human lung cancer (A-549) cell lines were obtained from the American Type Culture Collections (Manassas, VA, United States). They were cultured in RPMI 1640 medium (Biowhittaker, France) supplemented with $10 \%$ fetal bovine serum (Biowhittaker, France) at $37^{\circ} \mathrm{C}$ under a humidified atmosphere containing $5 \% \mathrm{CO}_{2}$. All cell lines were maintained as exponentially growing monolayers in mycoplasma free culture condition checked by polymerase chain reaction (PCR) analysis (PCR Mycoplasma Test Kit I/C, PromoKine, PromoCell France).

\section{Drug solutions}

The newly synthetized derivatives were diluted into dimethylsulfoxyde (DMSO) (Sigma, France). Reference molecules, approved in clinic for colon, breast or lung cancer, were obtained from commercial solutions : oxaliplatin (Oxaliplatine Dakota Pharm ${ }^{\circledR} 5 \mathrm{mg} / \mathrm{mL}$ ), 5-fluorouracil (Fluorouracil Accord ${ }^{\circledR} 50 \mathrm{mg} / \mathrm{mL}$ ) and paclitaxel (Paclitaxel Kabi ${ }^{\circledR} 6 \mathrm{mg} / \mathrm{mL}$ ). In cell culture, maximum concentration of DMSO did not exceed $3 \%$ in the medium.

\section{Assay of cytotoxicity in cancer cell lines}

SW 480, MDA-MB-231 and A-549 were seeded in 96-well plates at a density of 10,000 cells per well. Twenty four hours later, cells were treated for 48 hours by increasing concentrations (from 0 to $500 \mu \mathrm{M}$ or from 0 to $25 \mu \mathrm{M}$ according to the drug) of the newly synthetized or reference molecules. After treatment, cytotoxicity was assessed by crystal violet staining: cells were washed in Phosphate Buffered Saline (PBS) $1 \times$, fixed in pure ethanol, stained with $1 \%$ crystal violet, and eluted in $33 \%$ acetic acid. The intensity of coloration was determined by the measurement of absorbance by spectrophotometry (UVM 340, Bioserv) at $\lambda=570 \mathrm{~nm}$. Each concentration measurement was conducted in triplicate from three independent experiments.

Results were expressed as concentration-response curves, representing the percentage of cytotoxicity according to the concentration of the drug. From these curves, the 50\% Inhibitory Concentration (IC50), representing the concentration which inhibits $50 \%$ of cell growth, was calculated for each compound.

\section{Conflicts of interest}

"There are no conflicts to declare".

\section{Acknowledgements}

The Ministère de l'Enseignement Supérieur et de la Recherche, the Centre National de la Recherche Scientifique (CNRS), the Conseil Régional de Bourgogne, and the French Research National Agency (ANR) via project JCJC "SPID" ANR-16-CE07-0020 are gratefully acknowledged. This work is part of the projects "Pharmacoimagerie et agents théranostiques" et "Chimie durable, environnement et agroalimentaire" supported by the Université de Bourgogne and the Conseil Régional de 
Bourgogne through the Plan d'Actions Régional pour I'Innovation (PARI) and the European Union through the PO FEDER-FSE Bourgogne 2014/2020 programs. FrenchBIC, and GDR AIM are acknowledged for fruitful discussion. Ms M.-J. Penouilh and Mr. Q. Bonnin are gratefully acknowledged for HR-MS analysis.

\section{Notes and references}

1 R. Zurawinski, B. Donnadieu, M. Mikolajczyk and R. Chauvin, Organometallics, 2003, 22, 4810-4817.

2 P. Leglaye, B. Donnadieu, J.-J. Brunet and R. Chauvin, Tetrahedron Lett., 1998, 39, 9179-9182.

3 E. Ranaud, R. B. Russell, S. Fortier, S. J. Brown and M. C. Baird, J. Organomet. Chem., 1991, 419, 403-415.

4 I. J. B. Lin, H. C. Shy, C. W. Liu, L.-K. Liu and S.-K. Yeh, J. Chem. Soc. Dalton Trans., 1990, 2509-2514.

5 R. Usón, J. Forniés, R. Navarro and A. M. Ortega, J. Organomet. Chem., 1987, 334, 389-397.

6 C.-W. Lee, O. Kim and M.-S. Gong, J. Appl. Polym. Sci., 2003, 89, 1062-1070.

7 M. P. Murphy, Biochim. Biophys. Acta BBA - Bioenerg., 2008, 1777, 1028-1031.

8 J. Wang, C.-T. Yang, Y.-S. Kim, S. G. Sreerama, Q. Cao, Z.-B. Li, Z. He, X. Chen and S. Liu, J. Med. Chem., 2007, 50, 50575069.

9 R. A. J. Smith, C. M. Porteous, A. M. Gane and M. P. Murphy, Proc. Natl. Acad. Sci., 2003, 100, 5407-5412.

10 S. Kumari, S. Jayakumar, G. D. Gupta, S. C. Bihani, D. Sharma, V. K. Kutala, S. K. Sandur and V. Kumar, Free Radic. Biol. Med., 2019, 143, 140-145.

11 S. Jayakumar, R. S. Patwardhan, D. Pal, B. Singh, D. Sharma, V. K. Kutala and S. K. Sandur, Free Radic. Biol. Med., 2017, 113, 530-538.

12 K. Shioji, Y. Oyama, K. Okuma and H. Nakagawa, Bioorg. Med. Chem. Lett., 2010, 20, 3911-3915.

13 S. Samiee, N. Kooti, H. Motamedi, R. W. Gable and F. A. Bagherjeri, Polyhedron, 2015, 98, 120-130.

14 C. Roder and M. J. Thomson, Drugs RD, 2015, 15, 13-20.

15 T. Zou, C. T. Lum, C.-N. Lok, J.-J. Zhang and C.-M. Che, Chem. Soc. Rev., 2015, 44, 8786-8801.

16 P. J. Barnard, M. V. Baker, S. J. Berners-Price and D. A. Day, J. Inorg. Biochem., 2004, 98, 1642-1647.

17 R. Rubbiani, I. Kitanovic, H. Alborzinia, S. Can, A. Kitanovic, L. A. Onambele, M. Stefanopoulou, Y. Geldmacher, W. S. Sheldrick, G. Wolber, A. Prokop, S. Wölfl and I. Ott, J. Med. Chem., 2010, 53, 8608-8618.

18 R. Rubbiani, S. Can, I. Kitanovic, H. Alborzinia, M. Stefanopoulou, M. Kokoschka, S. Mönchgesang, W. S. Sheldrick, S. Wölfl and I. Ott, J. Med. Chem., 2011, 54, 8646-8657.

19 J. Ceramella, A. Mariconda, D. lacopetta, C. Saturnino, A. Barbarossa, A. Caruso, C. Rosano, M. S. Sinicropi and P. Longo, Bioorg. Med. Chem. Lett., 2020, 30, 126905.

20 C. Yeo, K. Ooi and E. Tiekink, Molecules, 2018, 23, 1410.

21 A. Sigel, H. Sigel, E. Freisinger and R. K. O. Sigel, Eds., Metallo-Drugs: Development and Action of Anticancer Agents, De Gruyter, Berlin, Boston, 2018.

22 B. Bertrand, M. R. M. Williams and M. Bochmann, Chem. - Eur. J., 2018, 24, 11840-11851.

23 C. Nardon, N. Pettenuzzo and D. Fregona, Curr. Med. Chem., 2016, 23, 3374-3403.

24 A. Trommenschlager, F. Chotard, B. Bertrand, S. Amor, P. Richard, A. Bettaïeb, C. Paul, J.-L. Connat, P. Le Gendre and E. Bodio, ChemMedChem, 2018, 13, 2408-2414.

25 A. Trommenschlager, F. Chotard, B. Bertrand, S. Amor, L. Dondaine, M. Picquet, P. Richard, A. Bettaïeb, P. L. Gendre, C. Paul, C. Goze and E. Bodio, Dalton Trans., DOI:10.1039/C7DT01377A.

26 J. Pliquett, S. Amor, M. Ponce-Vargas, M. Laly, C. Racoeur, Y. Rousselin, F. Denat, A. Bettaeib, P. Fleurat-Lessard, C. Paul, C. Goze and E. Bodio, Dalton Trans., DOI:10.1039/C8DT02364F.

27 T. Onodera, I. Momose and M. Kawada, Chem. Pharm. Bull. (Tokyo), 2019, 67, 186-191.

28 B. Bertrand and A. Casini, Dalton Trans. Camb. Engl. 2003, 2014, 43, 4209-4219.

29 L. Ortego, F. Cardoso, S. Martins, M. F. Fillat, A. Laguna, M. Meireles, M. D. Villacampa and M. C. Gimeno, J. Inorg. Biochem., 2014, 130, 32-37.

30 L. S. Melvin, Tetrahedron Lett., 1981, 22, 3375-3376.

31 M. B. Tollefson, J. J. Li and P. Beak, J. Am. Chem. Soc., 1996, 118, 9052-9061.

32 D. Moulin, S. Bago, C. Bauduin, C. Darcel and S. Jugé, Tetrahedron: Asymmetry, 2000, 11, 3939-3956.

33 M. Picquet, S. Stutzmann, I. Tkatchenko, I. Tommasi, J. Zimmermann and P. Wasserscheid, Green Chem., 2003, 5, 153162.

34 P. Barron, L. Engelhardt, P. Healy, J. Oddy and A. White, Aust. J. Chem., 1987, 40, 1545.

35 Y.-S. Chen, D. W. Allen, G. J. Tizzard, M. B. Pitak, S. J. Coles, N. A. Cross and N. Bricklebank, Eur. J. Med. Chem., 2017, $125,528-537$.

36 P.-E. Doulain, R. Decréau, C. Racoeur, V. Goncalves, L. Dubrez, A. Bettaieb, P. L. Gendre, F. Denat, C. Paul, C. Goze and E. Bodio, Dalton Trans., 2015, 44, 4874-4883.

Single crystals suitable for DRX analysis were obtained for le and If from biphasic dichloromethane / cyclohexane mixture. The structures determined by X-ray diffraction are presented in figures 2 and 3 . The structures of the two gold complexes le (ferrocenyl substituent on phosphonium) and If (methyl substituent on phosphonium) show similar data. The geometry 
around the gold atom is almost linear, characteristic of a phosphine-AuX complex. ${ }^{34}$ Nevertheless, the more bulky ferrocenyl group leads to a different organization of phosphonium moiety. The bond lengths around the gold atom in complexes le and If are similar to the $\mathrm{PPh}_{3} \mathrm{AuBr}$ complex (P-Au: 2.252(6); $\mathrm{Au}-\mathrm{Br}$ : 2.407 (2)). In le, intermolecular interactions in the crystal lead to a $\mathrm{P}-\mathrm{Au}-\mathrm{Br}$ angle of $172.73^{\circ}$.

\section{Anti-proliferative properties}

The anti-proliferative properties of the different gold(I) complexes la-f were evaluated onto three human cancer cell lines: A549 (lung carcinoma), MDA-MB-231 (breast adenocarcinoma), and SW480 (colorectal adenocarcinoma) (Table 3). Their IC S0 $_{50}$ were compared to three clinically used drugs: oxaliplatin used for the treatment of colorectal cancer, 5-fluorouracil (5-FU) used for colorectal, breast, and ovarian cancers, paclitaxel used for lung, breast, and ovarian cancers, and to a common $\mathrm{Au}(\mathrm{l})$-phosphine complex $\left[\mathrm{Au}\left(\mathrm{PPh}_{3}\right) \mathrm{Br}\right] \mathrm{Ig}$. All the tested complexes displayed strong anti-proliferative properties on the three cell lines. Their activities are in the range of paclitaxel but significantly better than oxaliplatin (up 30 times more efficient) and 5-FU (up to 120 times more efficient) (Figure 4). It is worth noting that Ig display an efficacy 10 to 100 times lower that the best complexes, which highlights the positive impact of the presence of the phosphonium moiety on antiproliferative activity. This can be explained by the fact that introducing a phosphonium greatly improves the water solubility of the complexes compared to non-containing phosphonium gold complexes (by about a factor of 100 comparing to $\left[\mathrm{Au}\left(\mathrm{PPh}_{3}\right) \mathrm{Br}\right]$, see ESI for details). 